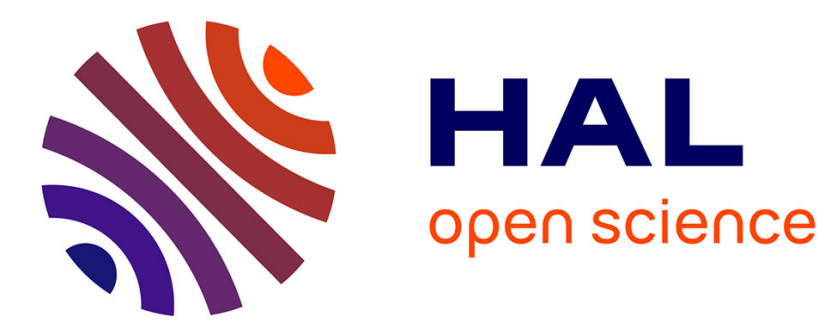

\title{
Semi-brittle flow of granitoid fault rocks in experiments
} Matej Pec, Holger Stünitz, Renée Heilbronner, Martyn Drury

\section{To cite this version:}

Matej Pec, Holger Stünitz, Renée Heilbronner, Martyn Drury. Semi-brittle flow of granitoid fault rocks in experiments. Journal of Geophysical Research: Solid Earth, 2016, 121, pp.1677-1705. 10.1002/2015JB012513 . insu-01293603

\section{HAL Id: insu-01293603 \\ https://hal-insu.archives-ouvertes.fr/insu-01293603}

Submitted on 4 Apr 2016

HAL is a multi-disciplinary open access archive for the deposit and dissemination of scientific research documents, whether they are published or not. The documents may come from teaching and research institutions in France or abroad, or from public or private research centers.
L'archive ouverte pluridisciplinaire HAL, est destinée au dépôt et à la diffusion de documents scientifiques de niveau recherche, publiés ou non, émanant des établissements d'enseignement et de recherche français ou étrangers, des laboratoires publics ou privés.

\section{(이)(\$)}

Distributed under a Creative Commons Attribution - NonCommercial - NoDerivatives| 4.0 


\section{QAGUPUBLICATIONS}

\section{Journal of Geophysical Research: Solid Earth}

\author{
RESEARCH ARTICLE \\ 10.1002/2015JB012513 \\ Key Points: \\ - Samples reach a high steady state \\ flow stress which is temperature, \\ normal stress and rate dependent \\ - Deformation partitions into \\ anastomozing layers containing \\ nanocrystaline and amorphous \\ material \\ - Nanocrystalline/amorphous slip zones \\ could trigger earthquakes after long \\ periods of slow creep
}

Correspondence to:

M. Pec,

mpec@umn.edu;

matej.pec@seznam.cz

Citation:

Pec, M., H. Stünitz, R. Heilbronner, and M. Drury (2016), Semi-brittle flow of granitoid fault rocks in experiments, J. Geophys. Res. Solid Earth, 121, doi:10.1002/2015JB012513.

Received 21 SEP 2015

Accepted 21 FEB 2016

Accepted article online 26 FEB 2016

C2016. American Geophysical Union. All Rights Reserved.

\section{Semi-brittle flow of granitoid fault rocks in experiments}

\author{
Matej Pec ${ }^{1,2}$, Holger Stünitz ${ }^{3,4}$, Renée Heilbronner ${ }^{1}$, and Martyn Drury ${ }^{5}$ \\ ${ }^{1}$ Geological Institute, Basel University, Basel, Switzerland, ${ }^{2}$ Department of Earth Sciences, University of Minnesota, Twin \\ Cities, Minneapolis, USA, ${ }^{3}$ Department of Geology, Troms $\varnothing$ University, Troms $\varnothing$, Norway, ${ }^{4}$ Institut des Sciences de la Terre \\ d'Orléans, Université d'Orléans, Orléans, France, ${ }^{5}$ Department of Earth Sciences, Utrecht University, Utrecht, Netherlands
}

Abstract Field studies and seismic data show that semi-brittle flow of fault rocks probably is the dominant deformation mechanism at the base of the seismogenic zone at the so-called frictional-viscous transition. To understand the physical and chemical processes accommodating semi-brittle flow, we have performed an experimental study on synthetic granitoid fault rocks exploring a broad parameter space (temperature, $T=300$, 400,500 , and $600^{\circ} \mathrm{C}$, confining pressure, $P_{c} \approx 300,500,1000$, and $1500 \mathrm{MPa}$, shear strain rate, $\dot{\gamma} \approx 10^{-3}, 10^{-4}$, $10^{-5}$, and $10^{-6} \mathrm{~s}^{-1}$, to finite shear strains, $\left.\gamma=0-5\right)$. The experiments have been carried out using a granular material with grain size smaller than $200 \mu \mathrm{m}$ with a little $\mathrm{H}_{2} \mathrm{O}$ added $(0.2 \mathrm{wt} \%)$. Only two experiments (performed at the fastest strain rates and lowest temperatures) have failed abruptly right after reaching peak strength $(\tau \sim 1400 \mathrm{MPa})$. All other samples reach high shear stresses $(\tau \sim 570-1600 \mathrm{MPa})$ then weaken slightly (by $\Delta \tau \sim 10-190 \mathrm{MPa}$ ) and continue to deform at a more or less steady state stress level. Clear temperature dependence and a weak strain rate dependence of the peak as well as steady state stress levels are observed. In order to express this relationship, the strain rate-stress sensitivity has been fit with a stress exponent, assuming $\gamma^{\cdot} \propto \tau^{\mathrm{n}}$ and yields high stress exponents $(n \approx 10-140)$, which decrease with increasing temperature. The microstructures show widespread comminution, strain partitioning, and localization into slip zones. The slip zones contain at first nanocrystalline and partly amorphous material. Later, during continued deformation, fully amorphous material develops in some of the slip zones. Despite the mechanical steady state conditions, the fabrics in the slip zones and outside continue to evolve and do not reach a steady state microstructure below $\gamma=5$. Within the slip zones, the fault rock material progressively transforms from a crystalline solid to an amorphous material. We present and interpret the experimental results both in terms of sliding friction and viscous flow, and we discuss the possible effect that the formation of nanocrystalline and amorphous layers may have on earthquake nucleation.

\section{Introduction}

Fault zones, which accommodate plate tectonic movement, limit the strength of the lithosphere and operate under a broad range of pressure and temperature conditions. Within a single fault zone, strain localization and partitioning occur at different depths to accommodate the imposed movement. Depending on the pressure, temperature, and strain rate conditions as well as the presence of fluids, the rocks will either flow viscously or dilate, fracture, and slide frictionally. Depending on how much strain is accommodated by the viscous component (diffusive mass transfer processes, dislocation motion, and grain boundary sliding) and by the frictional component (fracturing, granular flow, and frictional sliding), the rheological response will be either more viscous or more frictional. The rheological behavior of rocks under purely viscous and purely frictional conditions is relatively well understood. However, this is not the case when both sets of processes interact.

With increasing depth, the strength of the lithosphere increases until it reaches a maximum near the so-called "frictional-viscous" transition where the rocks deform by semi-brittle flow and where the operation of both frictional as well as viscous processes is likely [e.g., Kohlstedt et al., 1995; Stöckhert et al., 1999; White, 2001]. Under these conditions, a load-bearing layer is expected to have the largest potential for nucleating major earthquakes by abruptly releasing the stored elastic energy.

Originally, the frictional-viscous transition was inferred to occur at the depth where Byerlee's rule for frictional sliding intersects a flow law for steady state creep (for a given geothermal gradient and bulk strain rate) [Goetze and Evans, 1979; Brace and Kohlstedt, 1980]. However, it was soon recognized that in doing so both Byerlee's rule as well as steady state flow laws had been applied to physical conditions outside their range of validity [e.g., Carter and Tsenn, 1987]. Numerous attempts have been made to remedy this problem, and new definitions for the frictional-viscous transition have been proposed [e.g., Scholz, 1988, Shimada, 1993; 
Chester, 1995; Ohnaka, 1995; Blanpied et al., 1995; Kohlstedt et al., 1995; Stöckhert et al., 1999; White, 2001; Bos and Spiers, 2002a].

A large body of literature focuses on the mechanical behavior of rocks in the viscous as well as frictional field. Experiments in the semi-brittle field where both frictional as well as viscous processes operate are much less abundant. Despite efforts to connect empirical friction laws with steady state flow laws [e.g., Bos and Spiers, 2002a; Niemeijer and Spiers, 2007; Noda and Shimamoto, 2010, 2012] no widely acknowledged flow or friction law, which would facilitate the analysis of the rheological behavior in the semi-brittle field, is available to date. We will briefly elaborate why the rate-and-state laws for frictional sliding and the flow laws for viscous flow are difficult to reconcile.

\subsection{Fracture and Frictional Sliding}

Under conditions of low temperature, low-pressure and high-stress rocks fracture and lose cohesion along fractures, which may evolve to gouge-filled shear zones. The orientation of a macroscopic fracture can be predicted using the Mohr-Coulomb failure criterion:

$$
\tau=\mathrm{C}+f \sigma_{\mathrm{n}}
$$

where $\tau$ is the shear stress, $C$ the cohesion, $f=\tan (\phi)$, where $\phi$ is the angle of internal friction and $\sigma_{\mathrm{n}}$ is the normal stress acting on the fracture plane. Fractures form at approximately $30^{\circ}$ with respect to the maximal compressive stress as a result of coalescence of mode I cracks at low confining pressures [Paterson and Wong, 2005, pp. 127-128]. At higher confining pressures fracture forms at a higher angle as mode II/III cracks coalesce [Hirth and Tullis, 1994].

Once a through-going fracture is developed, frictional sliding on the existing failure surface limits the rock strength as described by Amonton's law:

$$
\tau=\mu \sigma_{\mathrm{n}}
$$

where $\tau$ is the shear stress, $\mu$ is the coefficient of friction, and $\sigma_{\mathrm{n}}$ is the normal stress. Frictional sliding depends primarily on the normal stress due to the inherent need for dilatancy when individual fragments slide past each other and have to do work against the normal stress [e.g., Marone, 1998]. The friction coefficient is linearly dependent on normal stress over a certain range of pressure-temperature (P-T) conditions. At elevated confining pressures, the rocks reach a maximum compressive strength, i.e., the shear stress becomes independent of normal stress [Ohnaka, 1995; Renshaw and Schulson, 2007].

Empirical rate-and-state-dependent friction laws [Dieterich, 1978; Ruina, 1983] are successfully used to model the mechanical response of simulated fault surfaces (gouge-filled as well as rock-on-rock contact) under moderate normal stresses (usually $\sigma_{\mathrm{n}}<<500 \mathrm{MPa}$ ) to the applied sliding velocity. Rate-and-state friction laws have several forms; we take the common form for steady state friction [e.g., Scholz, 1998]:

$$
\tau=\left[\mu_{0}+(a-b) \ln \left(\frac{V}{V_{0}}\right)\right] \sigma_{n}
$$

where $\mu_{0}$ is the steady state friction coefficient at reference velocity (displacement rate) $V_{0}, V$ is the slip velocity, and $a$ and $b$ are empirical variables denoting material properties.

\subsection{Viscous Flow}

Under conditions of high temperature and high pressure, rocks deform by viscous flow. Strain compatibility is maintained by a combination of dislocation glide and climb, diffusion and dissolution-precipitation creep, and grain boundary sliding; all of which are in essence mass transfer processes depending on atomic mobility, i.e., on temperature and time. Viscous flow laws are typically divided into power-law flow laws, which describe the flow in high-temperature ( $T>0.6 T_{m}$, where $T_{m}$ is the melting temperature), low stress environments, and exponential flow laws, which are appropriate for low-temperature $\left(T<0.6 T_{m}\right)$, high stress environments. In both regimes the differential stresses have to be lower than the confining pressures $\left(\Delta \sigma<\mathrm{P}_{\mathrm{c}}\right)$ to suppress fracturing. Power-law flow laws have the general form of

$$
\dot{\varepsilon}=A \sigma^{n} d^{-m} \exp \left(\frac{-E+P V}{R T}\right),
$$

where $\dot{\varepsilon}$ is the strain rate, $A$ is the pre-exponential constant dependent on the microphysical process under study, $\sigma$ the differential stress, $n$ the stress exponent, $d$ the grain size, $m$ the grain size exponent, $E$ the 
activation energy, $P$ the pressure, $V$ the activation volume, $R$ the gas constant, and $T$ the temperature. Typical stress exponents, $n$, are in the range from 1 to 5, depending on the accommodation processes [e.g., Koh/stedt and Hansen, 2015]. Exponential flow laws have the general form of

$$
\dot{\varepsilon}=B \sigma^{2} \exp \left\{\left(\frac{-H_{0}}{R T}\right)\left[1-\left(\frac{\sigma}{\sigma_{P}}\right)^{p}\right]^{q}\right\}
$$

where $B$ is a material dependent constant, $H_{0}$ is the activation enthalpy at zero stress, $\sigma_{\mathrm{p}}$ is the Peierls stress (lattice friction), and the $p$ and $q$ are model-dependent parameters which describe the geometry of obstacles resisting dislocation glide [e.g., Evans and Goetze, 1979; Mei et al., 2010].

Note that rate-and-state friction laws relate shear stress to normal stress under conditions of constant displacement rate, whereas the viscous flow laws describe strain rate as a function of flow stress, temperature, grain size, and other state variables. Experimental studies are designed to either test for the material constants $a$ and $b$ (friction) or to derive $A, n, E, V$, and $m$ (power-law flow) or $B, H, \sigma_{p}, p$, and $q$ (exponential flow). The relation between the parameters $a$ and $b$ on the one hand and $A, n, E, V$, and $m$ or $B, H, \sigma_{p}, p$, and $q$ on the other hand is not at all straightforward.

\subsection{Frictional-Viscous Transition and Semi-brittle Behavior}

In the viscous field, the underlying microphysical processes causing the observed rheological behavior are relatively well understood [e.g., Kohlstedt and Hansen, 2015]. But, despite many efforts, the rate-and-state frictional laws remain empirical in nature [e.g., Chester, 1994; Marone, 1998], and their underlying physics is elusive despite some promising development in the last years [see, e.g., Niemeijer and Spiers, 2006; Beeler et al., 2007; Den Hartog et al., 2014; Verberne et al., 2014].

Generally, semi-brittle behavior exhibits both frictional characteristics (peak stress increases with increasing pressure and is relatively insensitive to the rate of deformation and temperature) as well as viscous characteristics (peak stress shows a strong strain rate and temperature dependence and is relatively insensitive to pressure).

Semi-brittle behavior can arise due to a variety of reasons under a broad range of thermomechanical conditions in experiments as well as nature. In monophase aggregates, semi-brittle behavior occurs at high differential stresses (typically $\Delta \sigma>P_{c}$ ), low homologous temperatures $\left(T_{h}=T / T_{m}\right)$-which inhibit efficient strain accommodation by viscous processes, and high pressures-which inhibit frictional sliding. Deformation is then accommodated by a combination of microfracturing and dislocation motion and/or twinning [e.g., Kirby and Kronenberg, 1984; Tullis and Yund, 1987; Hirth and Tullis, 1994; Schubnel et al., 2006; Brantut et al., 2011; Druiventak et al., 2011].

Furthermore, in polyphase aggregates, semi-brittle behavior can occur at such thermomechanical conditions where some of the individual phases can accommodate strain by viscous flow, while other phases fracture [e.g., Bos et al., 2000; Bos and Spiers, 2002b; Niemeijer and Spiers, 2005, 2006; Violay et al., 2012; Reber et al., $2014,2015]$. The viscously deforming phase can either be a different mineral or can form due to microstructural transformations. For example, grain-size reduction due to fracturing, together with the presence of fluids, can promote viscous flow (dissolution-precipitation creep) in some part of the fine-grained aggregate [Blanpied et al., 1991, 1995, 1998; Keulen et al., 2007, 2008; Pec et al., 2012a].

The complex causes of semi-brittle behavior together with the discrepancy between the theoretical frameworks, and the narrow overlap of $\mathrm{P}-\mathrm{T}-\dot{\varepsilon}$ conditions explored in experimental studies in the frictional and viscous regime, are partly responsible for our poor understanding of the mechanics of semi-brittle flow.

In this study we contribute new data from rock-deformation experiments performed under a wide range of conditions on granitoid cataclasites where the rocks deform by semi-brittle flow (Figure 1). The experimental pressure and temperature conditions correspond to those of a range of tectonic settings from the base of the seismogenic layer on strike-slip faults to subduction zones. We present the mechanical data with both the frictional and the viscous interpretations in mind: in terms of sliding of two blocks across a very thick fault surface and in terms of flow of a very thin volume of fault rock between two forcing blocks. We complement the mechanical data with previously reported microstructural data [Pec et al., 2012a, $2012 \mathrm{~b}$ ] in order to explain the evolution of the fault rocks and to infer the active deformation processes in the semi-brittle field. 


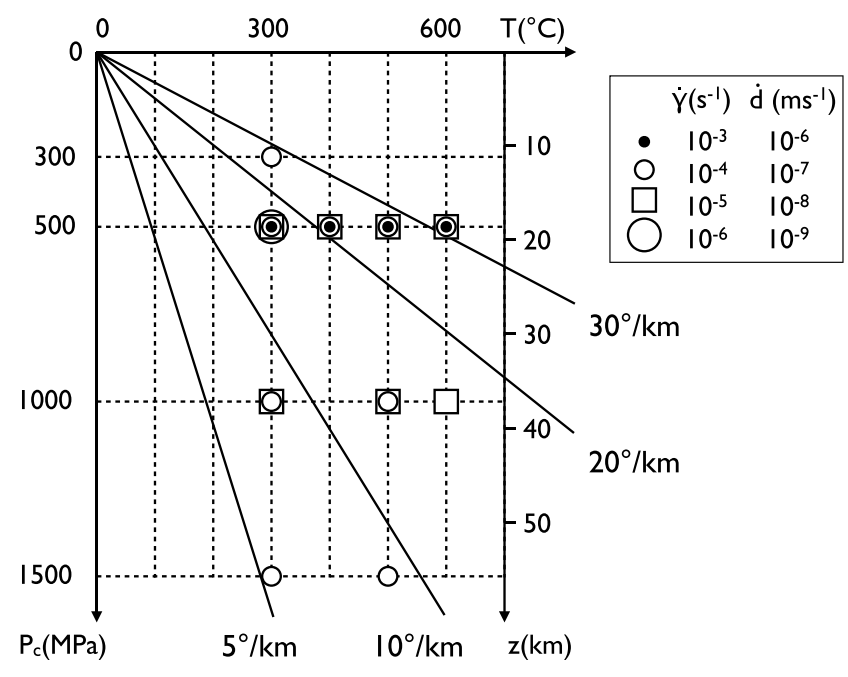

Figure 1. Experimental conditions. Experiments were carried out at temperatures $T=300-600^{\circ} \mathrm{C}$ and confining pressures, $P_{C}=300-1500 \mathrm{MPa}$. Shear strain rates were $\dot{\gamma}=10^{-3}$ to $10^{-6} \mathrm{~s}^{-1}$ corresponding to piston displacement rates $\dot{d}=10^{-6}$ to $10^{-9} \mathrm{~m} \mathrm{~s}^{-1}$.

\section{Experimental Methods}

We have performed a series of general shear, constant displacement rate experiments in a solid-medium deformation apparatus (modified Griggs rig) on granular fault rocks $\left(d_{\text {equ }}<200 \mu \mathrm{m}\right)$ prepared from intact Verzasca gneiss. The Verzasca gneiss powder consists of $37 \%$ quartz, $33 \%$ plagioclase, $28 \%$ potassium feldspar, and $2 \%$ of micas (see Figure 9 in Pec et al. [2012a] for the microstructure of pressurized but otherwise undeformed starting material). To prepare the sample, $0.1 \mathrm{~g}$ (standard deviation $=6 \times 10^{-4} \mathrm{~g}$ ) of the crushed powder with $0.2 \mu \mathrm{L}$ (=0.2 wt \%) water added is placed between alumina forcing blocks precut at $45^{\circ}$ (Figure 2a). The forcing blocks are roughened by grinding with a silicon carbide powder (grain size $=150 \mu \mathrm{m}$ ) to assure good grip.

This assembly is then placed into annealed $\left(\sim 2 \mathrm{~h}\right.$ at $\left.900^{\circ} \mathrm{C}\right)$ platinum jackets (wall thickness of $\left.0.15 \mathrm{~mm}\right)$ with a thin nickel foil insert (thickness of $0.025 \mathrm{~mm}$ ) and weld sealed using a Lampert precision welding apparatus and a cooled brass heat sink to assure maintaining of the added water content. At the top and bottom of the weldsealed sample, alumina pistons $(\varnothing=6.33 \mathrm{~mm})$ are placed and together with the sample are fitted into potassium iodide (KI) inner salt liners. $\mathrm{Kl}$ is considerably weaker than $\mathrm{NaCl}$ at the employed experimental conditions [Inoue, 1957] allowing for a better stress resolution. Around the sample and the KI inner salt cell a graphite resistivity furnace (length $=35.7 \pm 0.02 \mathrm{~mm}$ ) is inserted, which is surrounded by outer salt liners made of sodium chloride ( $\mathrm{NaCl}$ ).

The temperature is controlled with a proportional integral derivative (PID) controller (Eurotherm) attached to a K-type thermocouple touching the center of the shear zone (see Figure 1 in Pec et al. [2012b] for assembly drawing). Heat conduction in the sample assembly is high. The fastest quenching rates achievable by turning off the furnace allow quenching of the sample with a temperature decrease from $600^{\circ} \mathrm{C}$ to $\sim 30^{\circ} \mathrm{C}$ in less than $30 \mathrm{~s}$. There is a vertical temperature gradient from the center of the sample in both directions ranging from $\sim 5^{\circ} \mathrm{C} \mathrm{mm}^{-1}$ at $300^{\circ} \mathrm{C}$ to $\sim 17^{\circ} \mathrm{C} \mathrm{mm}^{-1}$ at $600^{\circ} \mathrm{C}$ [Peč, 2014, pp. 19-20].

\subsection{Experimental Procedure}

The sample assembly is placed in a water-cooled pressure vessel and inserted in the deformation apparatus. The confining pressure $\left(P_{c}\right)$ is monitored via oil pressure in the hydraulic pumping system and the force on the $\sigma_{1}$-piston is recorded with an external load cell. Displacement of the $\sigma_{1}$ piston is measured externally with two devices - a direct current displacement transducer (resolution $\sim 1 \mu \mathrm{m}$ ) and a noiseless digital linear transformation measurement system (resolution $=0.1 \mu \mathrm{m}$ ).

Advancing the confining pressure ram leads to salt collapse around the sample and buildup of the confining pressure. Heating is performed in $100^{\circ} \mathrm{C}$ steps at a rate of $0.33^{\circ} \mathrm{C} \mathrm{s}^{-1}$. Once the desired $P_{c}-T$ conditions are reached (typically in 5-8h), the $\sigma_{1}$ motor is started at an approximately constant displacement rate of $\sim 10^{-6}, 10^{-7}$, $10^{-8}$, or $10^{-9} \mathrm{~m} \mathrm{~s}^{-1}$ (corresponding to $30-0.03 \mathrm{~m} / \mathrm{yr}$ ) thus covering a large range of naturally occurring slip velocities in fault zones [Rowe and Griffith, 2015]. During the experiment, the temperature is held constant with the PID controller. At the end of the experiment, after reaching the desired piston displacement, the samples are quenched by ramping down to $200^{\circ} \mathrm{C}$ within $90 \mathrm{~s}$ using the PID controller resulting in varying quenching rates of $1.1^{\circ} \mathrm{C} \mathrm{s}^{-1}$ to $4.4^{\circ} \mathrm{C} \mathrm{s}^{-1}$ for samples deformed at $300^{\circ} \mathrm{C}$ to $600^{\circ} \mathrm{C}$, respectively. During quenching the load is removed from the sample until a remaining differential stress of $\sim 100 \mathrm{MPa}$ is reached so as to minimize unloading cracks. Finally, the confining pressure, load, and temperature are decreased together until room conditions are reached (typically over a period of $\sim 2-4 \mathrm{~h}$ ). The whole experiment (pressurization-deformation-depressurization) takes between $\sim 8$ and $100 \mathrm{~h}$ depending on the selected displacement rate. 

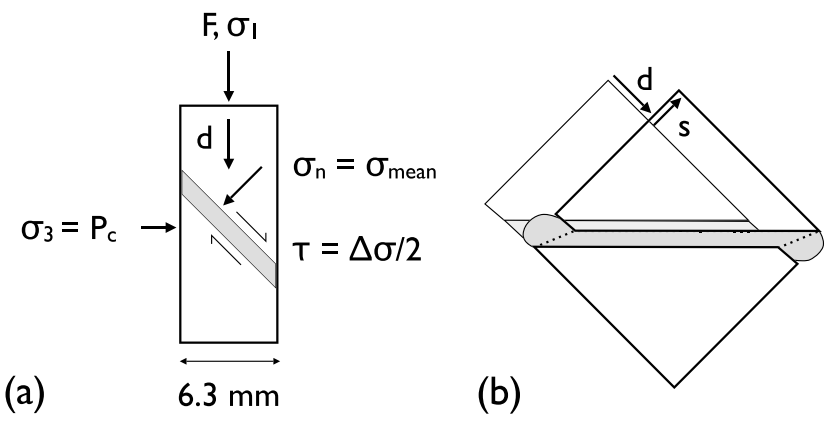

(c)

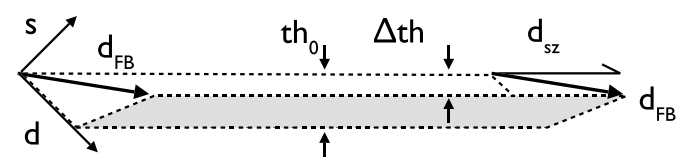

(d)

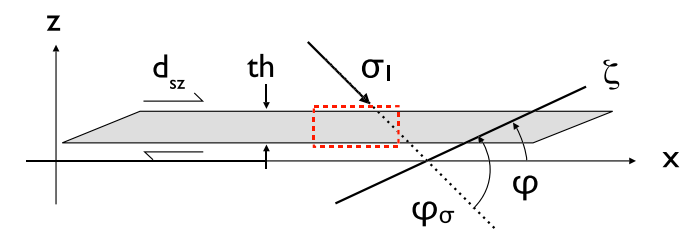

Figure 2. Sample assembly and geometry. (a) Experimental assembly: $45^{\circ}$ shear zone (light gray) between $\mathrm{Al}_{2} \mathrm{O}_{3}$ forcing blocks (white). $F=$ applied load, $\sigma_{1}=$ maximum compressive stress, $P_{C}=$ confining pressure, $\sigma_{\mathrm{n}}=$ normal stress on shear zone, $\tau=$ shear stress on shear zone, where $\Delta \sigma=\left(\sigma_{1}-\sigma_{3}\right)$. (b) Deformed sample: $d=$ displacement of forcing block parallel to $\sigma_{1}, s=$ side-way escape. Sample is extruded parallel to shear direction. (c) Sample strain is calculated as "gap strain" between forcing blocks: $d_{\mathrm{FB}}=$ total displacement of forcing block, $s$ and $d=$ components of $d_{\mathrm{FB}}$ as shown in Figure $2 \mathrm{~b}$. In terms of shear zone coordinates, the components of $d_{\mathrm{FB}}$ are $d_{\mathrm{SZ}}$ and $\Delta t h$ where $d_{\mathrm{SZ}}=$ displacement of forcing block parallel to shear zone, $\Delta t h=t_{0^{-}}$th $=$thinning of shear zone; $t_{O}=$ original thickness of shear zone. (d) Shear zone geometry: $(x, y, z)=$ structural coordinates, $d_{\mathrm{SZ}}=$ displacement parallel to shear zone, $t h=$ thickness of shear zone. $\zeta=$ planar or linear element, $\phi_{\sigma}=$ orientation of $\zeta$ with respect to sample axis, $\phi=$ orientation of $\zeta$ with respect to shear zone boundary. Red dashed rectangle indicates area used for quantitative microstructural analysis.

of thinning $\left(\Delta t h=t h_{0}-t h_{\text {final }}\right)$ is distributed linearly over the entire duration of the experiment. Mean bulk shear strain rates of $10^{-3}, 10^{-4}, 10^{-5}$ and $10^{-6} \mathrm{~s}^{-1}$ at displacement rates of $\sim 10^{-6}, 10^{-7}, 10^{-8}$, and $10^{-9} \mathrm{~m} \mathrm{~s}^{-1}$, respectively, are reached (see Table 1 for accurate values). Note that the progressive thinning may cause an increase of the shear strain rate, $\dot{\gamma}$, of up to 2 times from the beginning to the end of the experiment.

The final (or total) shear strain of a sample can be determined in two ways: it can be calculated from the total displacement of the piston $\left(\gamma_{\text {calc }}\right)$ or it can be measured on the thin section $\left(\gamma_{\text {meas }}\right)$. On average, there is a 1:1 relation between these two measurements but with a large scatter and without any systematic dependence on temperature, displacement rate, or confining pressure (Figure $3 \mathrm{~b}$ ). The measured finite shear strain in thin sections is taken as the more reliable one, and therefore, the progressive shear strain during the experiments is calculated as follows:

$$
\gamma(t)=\left(\gamma_{\text {meas }} / \gamma_{\text {calc }}\right) \cdot \gamma_{\text {pd }}(t)
$$

where $\gamma(t)=$ corrected shear strain and $\gamma_{\mathrm{pd}}(t)=$ shear strain determined from the piston displacement at time $t$. 


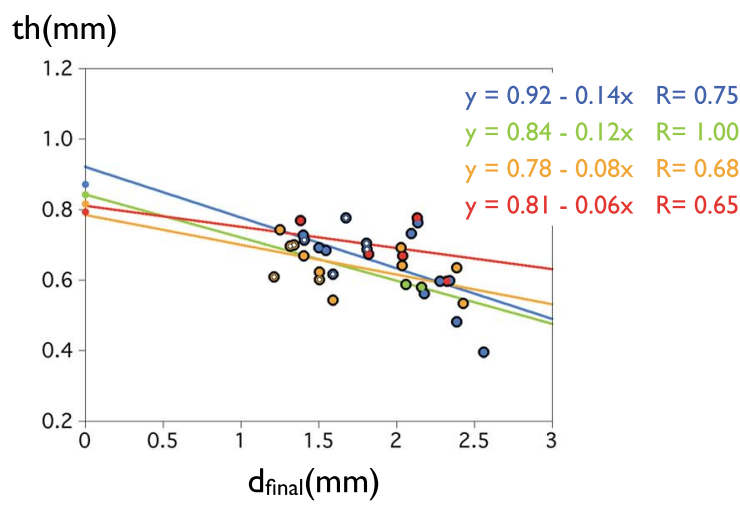

(a)

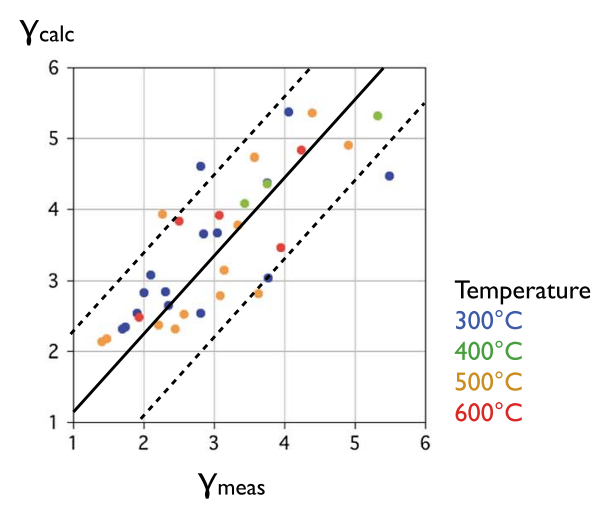

(b)

Figure 3. Shear strain and thinning of samples. (a) Decrease of shear zone thickness (th) during experiment: measured final thickness of shear zone versus final shear strain; an initial thickness (at $d=0 \mathrm{~mm}$ ) is calculated for different deformation temperatures (see text). (b) Calculated versus measured shear strain: $\gamma_{\text {meas }}$ is determined from the final offset of the forcing blocks after the experiment; $\gamma_{\text {calc }}$ is derived from the total piston displacement and total thinning of the shear zone.

Table 1. Summary of Performed Experiments ${ }^{a}$

\begin{tabular}{|c|c|c|c|c|c|c|c|c|c|c|c|c|c|}
\hline Sample & $T\left({ }^{\circ} \mathrm{C}\right)$ & $t(\mathrm{~s})$ & $\dot{d}\left(\mathrm{~m} \mathrm{~s}^{-1}\right)$ & $\dot{\gamma}\left(\mathrm{s}^{-1}\right)$ & $\gamma_{\text {calc }}$ & $\gamma_{\text {meas }}$ & $\begin{array}{c}P_{c}=\sigma_{3} \\
(\mathrm{MPa})\end{array}$ & $\tau(\mathrm{MPa})$ & $\sigma_{\mathrm{n}}(\mathrm{MPa})$ & $\mu$ & $d_{\text {vertical }}(\mathrm{mm})$ & $d_{\mathrm{sz}}(\mathrm{mm})$ & $\begin{array}{l}\text { SZ Thickness } \\
(\mathrm{mm})\end{array}$ \\
\hline 310 & 300 & 18240 & $1.25 \times 10^{-7}$ & $3.01 \times 10^{-4}$ & 4.47 & 5.49 & 311 & 1056 & 1555 & 0.68 & 2.28 & 2.67 & 0.597 \\
\hline 282 & 300 & 1320 & $1.28 \times 10^{-6}$ & $1.75 \times 10^{-3}$ & 2.84 & 2.31 & 502 & 1525 & 2263 & 0.67 & 1.69 & 2.21 & 0.778 \\
\hline 311 & 300 & 1300 & $1.34 \times 10^{-6}$ & $2.90 \times 10^{-3}$ & 3.03 & 3.76 & 509 & 1524 & 2248 & 0.68 & 1.74 & 2.09 & 0.688 \\
\hline 251 & 300 & 11580 & $1.38 \times 10^{-7}$ & $1.73 \times 10^{-4}$ & 2.83 & 2.01 & 512 & 1300 & 1994 & 0.65 & 1.60 & 1.75 & 0.618 \\
\hline 261 & 300 & 10020 & $1.39 \times 10^{-7}$ & $2.80 \times 10^{-4}$ & 2.54 & 2.80 & 517 & 1040 & 1654 & 0.63 & 1.40 & 1.07 & 0.42 \\
\hline 288 & 300 & 16750 & $1.42 \times 10^{-7}$ & $2.42 \times 10^{-4}$ & 5.38 & 4.05 & 538 & 1355 & 2198 & 0.62 & 2.38 & 2.59 & 0.481 \\
\hline 291 & 300 & 16240 & $1.44 \times 10^{-7}$ & $1.73 \times 10^{-4}$ & 4.61 & 2.81 & 519 & 1400 & 2236 & 0.63 & 2.34 & 2.76 & 0.599 \\
\hline 279 & 300 & 173230 & $1.23 \times 10^{-8}$ & $1.76 \times 10^{-5}$ & 3.67 & 3.05 & 499 & 1393 & 2205 & 0.63 & 2.14 & 2.80 & 0.763 \\
\hline 287 & 300 & 110200 & $1.28 \times 10^{-8}$ & $1.58 \times 10^{-5}$ & 2.34 & 1.74 & 507 & 1260 & 1942 & 0.65 & 1.41 & 1.67 & 0.714 \\
\hline 317 & 300 & 150340 & $1.39 \times 10^{-8}$ & $1.89 \times 10^{-5}$ & 3.66 & 2.84 & 503 & 1305 & 2098 & 0.62 & 2.09 & 2.68 & 0.733 \\
\hline 318 & 300 & 786800 & $1.96 \times 10^{-9}$ & $2.98 \times 10^{-6}$ & 2.64 & 2.35 & 506 & 932 & 1612 & 0.58 & 1.55 & 1.81 & 0.685 \\
\hline 260 & 300 & 11180 & $1.34 \times 10^{-7}$ & $1.71 \times 10^{-4}$ & 2.54 & 1.91 & 1007 & 1541 & 2887 & 0.53 & 1.50 & 1.76 & 0.692 \\
\hline 328 & 300 & 176390 & $1.24 \times 10^{-8}$ & $2.12 \times 10^{-5}$ & 4.38 & 3.75 & 986 & 1495 & 3001 & 0.50 & 2.18 & 2.46 & 0.561 \\
\hline 262 & 300 & 11690 & $1.20 \times 10^{-4}$ & $1.45 \times 10^{-4}$ & 2.32 & 1.69 & 1463 & 1605 & 3548 & 0.45 & 1.40 & 1.69 & 0.728 \\
\hline 315 & 400 & 1750 & $1.24 \times 10^{-6}$ & $2.15 \times 10^{-3}$ & 4.36 & 3.76 & 516 & 1274 & 2062 & 0.62 & 2.16 & 2.53 & 0.58 \\
\hline 313 & 400 & 16470 & $1.25 \times 10^{-7}$ & $2.08 \times 10^{-4}$ & 4.08 & 3.43 & 526 & 1167 & 1944 & 0.60 & 2.06 & 2.40 & 0.588 \\
\hline 306 & 400 & 188650 & $1.30 \times 10^{-8}$ & $2.82 \times 10^{-5}$ & 5.32 & 5.32 & 492 & 1002 & 1820 & 0.55 & 2.46 & 2.88 & 0.541 \\
\hline 284 & 500 & 1640 & $1.24 \times 10^{-6}$ & $2.03 \times 10^{-3}$ & 3.78 & 3.34 & 531 & 1217 & 2052 & 0.59 & 2.03 & 2.62 & 0.692 \\
\hline 247 & 500 & 14130 & $9.31 \times 10^{-8}$ & $1.73 \times 10^{-4}$ & 2.32 & 2.45 & 490 & 983 & 1628 & 0.60 & 1.32 & 1.62 & 0.698 \\
\hline 253 & 500 & 9910 & $1.35 \times 10^{-7}$ & $2.22 \times 10^{-4}$ & 2.38 & 2.20 & 530 & 1123 & 1820 & 0.62 & 1.34 & 1.67 & 0.701 \\
\hline 289 & 500 & 17100 & $1.40 \times 10^{-7}$ & $2.09 \times 10^{-4}$ & 4.74 & 3.58 & 527 & 1154 & 2052 & 0.56 & 2.39 & 3.01 & 0.636 \\
\hline 290 & 500 & 15560 & $1.56 \times 10^{-7}$ & $2.82 \times 10^{-4}$ & 5.37 & 4.39 & 532 & 1094 & 1951 & 0.56 & 2.43 & 2.87 & 0.534 \\
\hline 278 & 500 & 162060 & $1.45 \times 10^{-8}$ & $3.03 \times 10^{-5}$ & 4.90 & 4.90 & 515 & 1028 & 1854 & 0.55 & 2.36 & 2.87 & 0.585 \\
\hline 286 & 500 & 124870 & $1.20 \times 10^{-8}$ & $2.90 \times 10^{-5}$ & 2.81 & 3.62 & 490 & 1019 & 1666 & 0.61 & 1.50 & 1.69 & 0.602 \\
\hline 255 & 500 & 9770 & $1.28 \times 10^{-7}$ & $1.51 \times 10^{-4}$ & 2.18 & 1.47 & 1011 & 1310 & 2621 & 0.50 & 1.25 & 1.62 & 0.744 \\
\hline 256 & 500 & 10940 & $1.37 \times 10^{-7}$ & $2.81 \times 10^{-4}$ & 2.79 & 3.08 & 1023 & 1225 & 2578 & 0.48 & 1.50 & 1.74 & 0.624 \\
\hline 329 & 500 & 135960 & $1.50 \times 10^{-8}$ & $1.67 \times 10^{-5}$ & 3.94 & 2.27 & 977 & 913 & 2415 & 0.38 & 2.04 & 2.53 & 0.642 \\
\hline 263 & 500 & 11265 & $1.41 \times 10^{-7}$ & $2.79 \times 10^{-4}$ & 3.14 & 3.14 & 1554 & 1236 & 3276 & 0.38 & 1.59 & 1.69 & 0.539 \\
\hline 266 & 500 & 10510 & $1.34 \times 10^{-7}$ & $2.45 \times 10^{-4}$ & 2.53 & 2.58 & 1514 & 1297 & 3287 & 0.39 & 1.40 & 1.69 & 0.669 \\
\hline 314 & 600 & 1500 & $1.55 \times 10^{-6}$ & $2.83 \times 10^{-3}$ & 4.84 & 4.24 & 526 & 1006 & 1871 & 0.54 & 2.32 & 2.89 & 0.597 \\
\hline 312 & 600 & 15100 & $1.20 \times 10^{-7}$ & $2.61 \times 10^{-4}$ & 3.46 & 3.95 & 496 & 915 & 1651 & 0.55 & 1.82 & 2.33 & 0.674 \\
\hline 307 & 600 & 110290 & $1.25 \times 10^{-8}$ & $1.75 \times 10^{-5}$ & 2.48 & 1.93 & 498 & 515 & 1193 & 0.43 & 1.38 & 1.91 & 0.77 \\
\hline 316 & 600 & 130250 & $1.56 \times 10^{-8}$ & $2.36 \times 10^{-5}$ & 3.93 & 3.07 & 504 & 709 & 1499 & 0.47 & 2.04 & 2.63 & 0.67 \\
\hline 330 & 600 & 152180 & $1.40 \times 10^{-8}$ & $1.64 \times 10^{-5}$ & 3.84 & 2.50 & 1009 & 769 & 2457 & 0.31 & 2.13 & 2.98 & 0.777 \\
\hline
\end{tabular}

${ }^{\mathrm{a}} T$ : temperature, $t$ : time, $\dot{d}$ : mean vertical piston displacement rate, $\dot{\gamma}$ : mean shear strain rate, $\gamma_{\text {calc: }}$ calculated shear strain from mechanical record, $\gamma_{\text {meas: }}:$ mea-

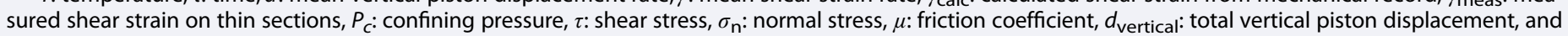
$d_{\mathrm{sz}}$ : total shear zone parallel displacement. $S Z$ : shear zone. 

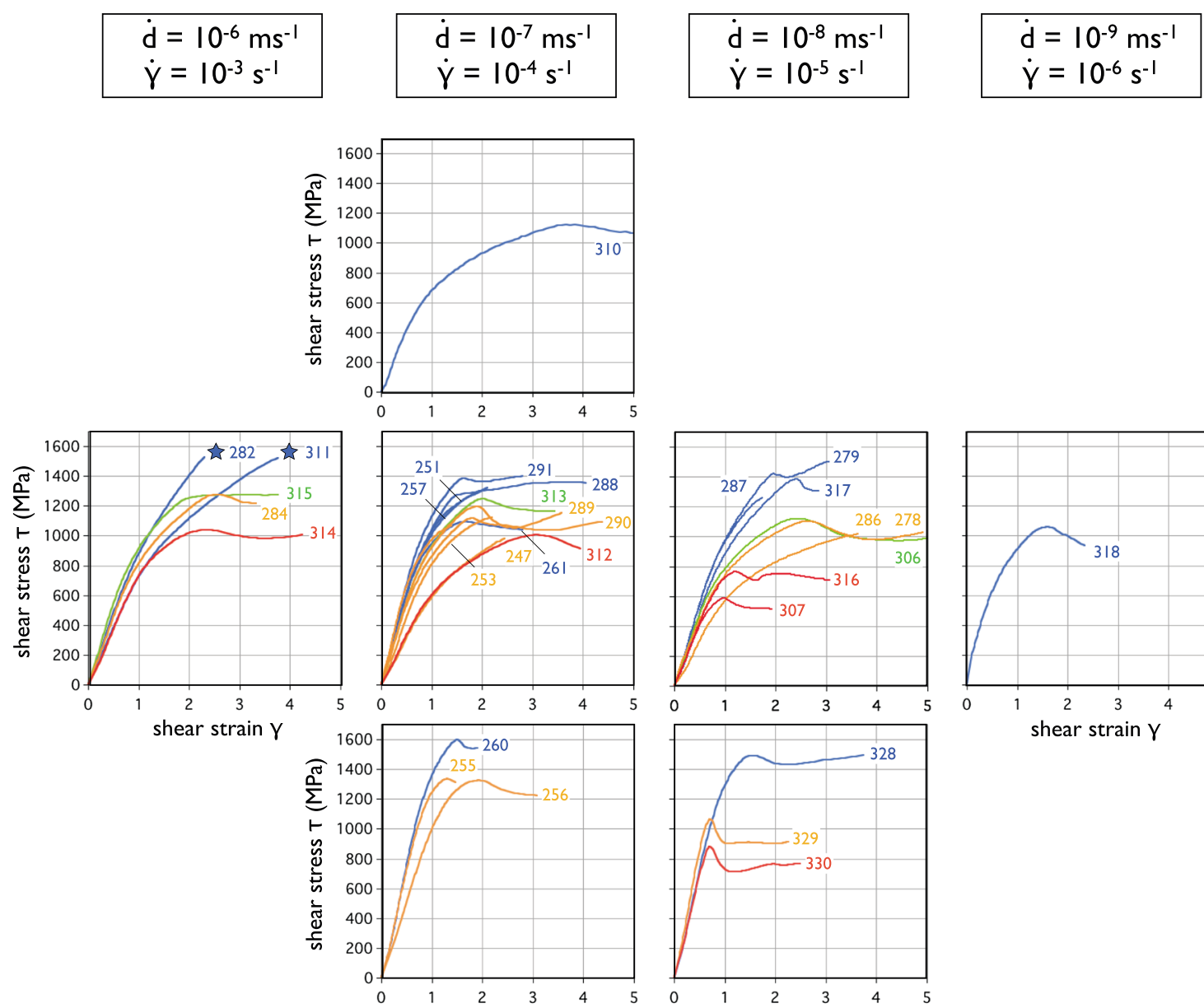

Temperature

$300^{\circ} \mathrm{C}$

$400^{\circ} \mathrm{C}$

$500^{\circ} \mathrm{C}$

$600^{\circ} \mathrm{C}$

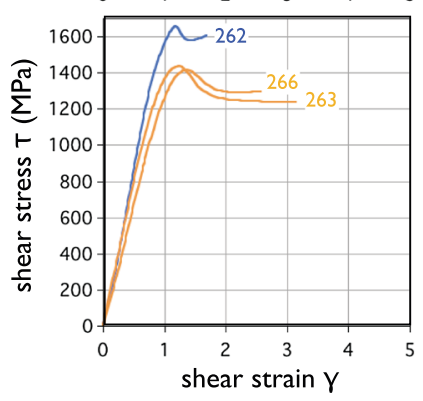

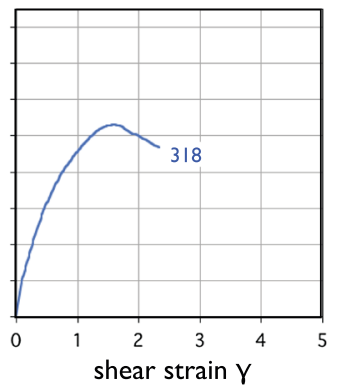

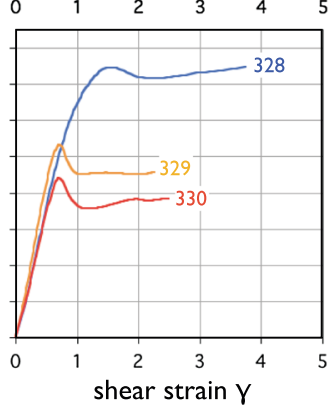

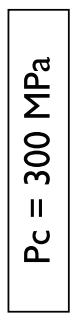
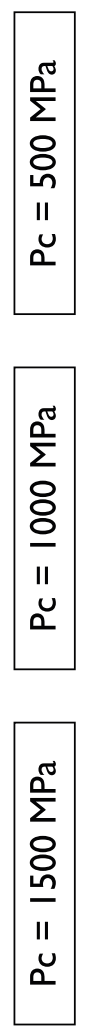

Figure 4. Strength of samples. Plots of shear stress $(\tau)$ versus shear strain $(\gamma)$ where $\gamma=$ corrected shear strain (see text); stars indicate abrupt failure. Rows: constant confining pressures $\left(P_{C}\right)$, columns: constant displacement rates of piston $(d)$, corresponding to constant shear strain rates of samples $(\dot{\gamma})$. Numbers label individual samples (see Table 1).

\section{Mechanical Results}

Stress-strain curves are shown in Figure 4, and friction coefficient-displacement curves are shown in Figure 5 for four different displacement rates $\left(\dot{d}_{\mathrm{sz}} \approx 10^{-6} \mathrm{~m} \mathrm{~s}^{-1}, 10^{-7} \mathrm{~m} \mathrm{~s}^{-1}, 10^{-8}\right.$, and $\left.10^{-9} \mathrm{~m} \mathrm{~s}^{-1}\right)$, i.e., shear strain rates $\left(\dot{\gamma} \approx 10^{-3} \mathrm{~s}^{-1}, 10^{-4} \mathrm{~s}^{-1}\right.$, and $\left.10^{-5} \mathrm{~s}^{-1}\right)$, and four different confining pressures $\left(P_{c}=300 \mathrm{MPa}, 500 \mathrm{MPa}\right.$, $1000 \mathrm{MPa}$, and $1500 \mathrm{MPa}$ ). To highlight the separate influences of $T$ and $\dot{\gamma}$ on strength, selected experiments are shown in Figures $6 \mathrm{a}$ and $6 \mathrm{~b}$, respectively.

\subsection{Influence of Strain Rate}

In all experiments, the stress level is weakly strain rate dependent, and this dependence becomes more pronounced at higher temperatures (Figure 6b). Samples failed abruptly (at $\tau \sim 1440 \mathrm{MPa}$ ) only when deformed 
fast $\dot{d}=10^{-6} \mathrm{~ms}^{-1}$ $\dot{\gamma}=10^{-3} \mathrm{~s}^{-1}$

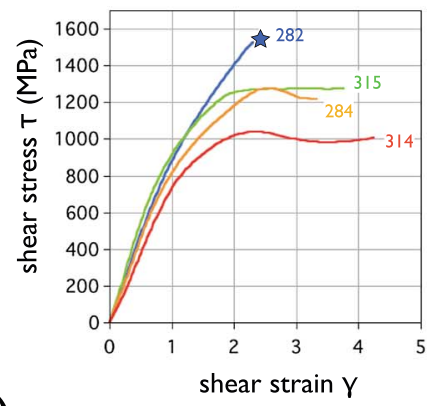

(a)

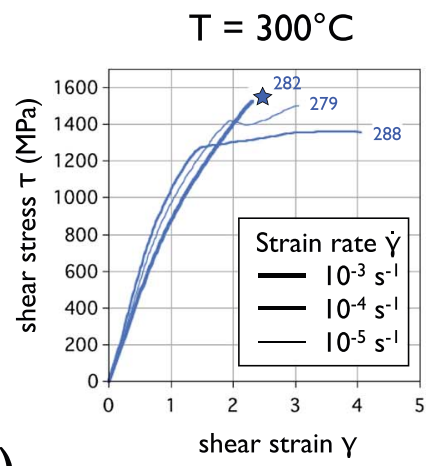

(b)

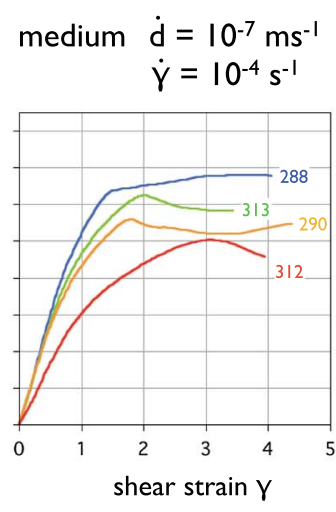

$\mathrm{T}=400^{\circ} \mathrm{C}$

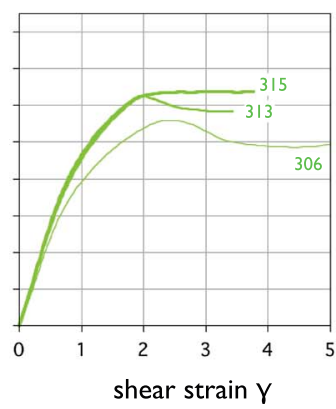

slow $\dot{d}=10^{-8} \mathrm{~ms}^{-1}$

$\dot{\gamma}=10^{-5} \mathrm{~s}^{-1}$

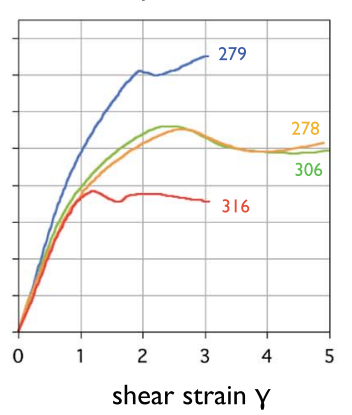

Temperature

$300^{\circ} \mathrm{C}$

$400^{\circ} \mathrm{C}$

$500^{\circ} \mathrm{C}$

$600^{\circ} \mathrm{C}$

Figure 6. Influence of displacement rate and temperature on flow stress at $P_{c}=500 \mathrm{MPa}$. (a) Results grouped by strain rate. (b) Results grouped by temperature. $\tau=$ shear stress, $\gamma=$ corrected shear strain, $\dot{d}=$ displacement rate of piston, $\dot{\gamma}=$ shear strain rate of samples. Note: Increasing $T$ decreases flow stress; the effect is most pronounced at slowest strain rates. Decreasing $\dot{\gamma}$ slightly decreases flow stress; the effect is more pronounced at higher temperature.

higher temperature experiments (Table 1 and Figures $6 \mathrm{a}$ and $6 \mathrm{~b}$ ). After the weakening, most of the samples continue to deform at a quasi-constant shear stress up to shear strains of $\sim 5$.

Expressing the temperature dependence of steady state stress at a confining pressure of $500 \mathrm{MPa}$ with an activation energy $Q(=E+P V$, see equation (4)) - assuming an Arrhenian temperature dependence-yields values of $Q=80-180 \mathrm{~kJ} / \mathrm{mol}$ for stress exponents ranging from 10 to 25 (Figure $7 \mathrm{~b}$ ). There appears to be an increase in
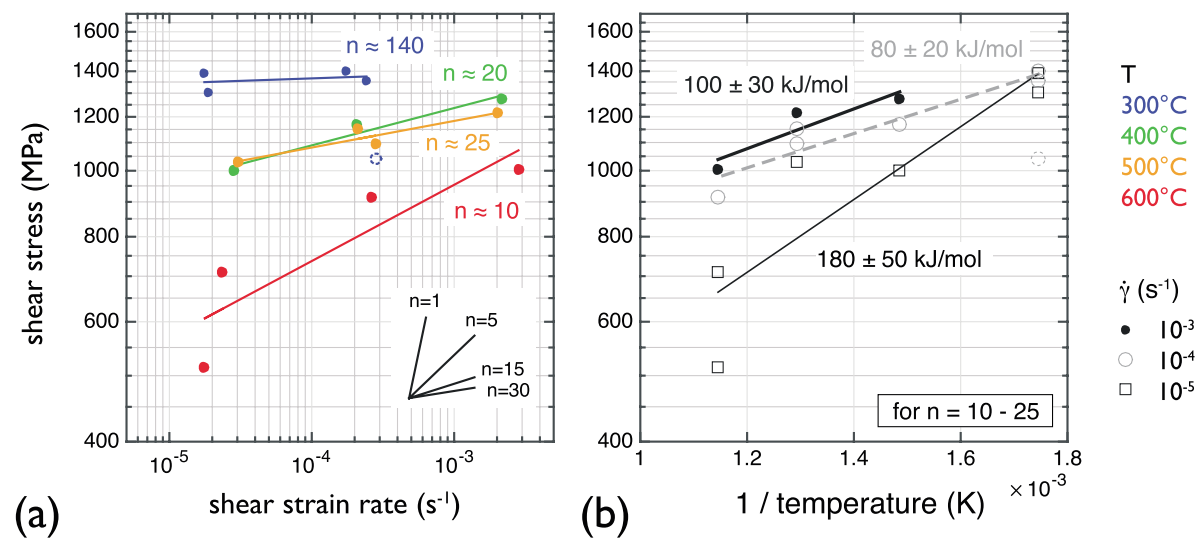

Figure 7. Rheological parameters. (a) Determination of the stress exponent $(n)$ at different temperatures. Full lines denote preferred fit, and dashed symbol is an outlier not used in the fit (\#261). (b) Arrhenius plot determining the activation energy at different strain rates assuming a stress exponent in the range of 10-25. As we performed constant displacement rate experiments, stress is an independent variable and is hence plotted on the $y$ axis. See text for details. 


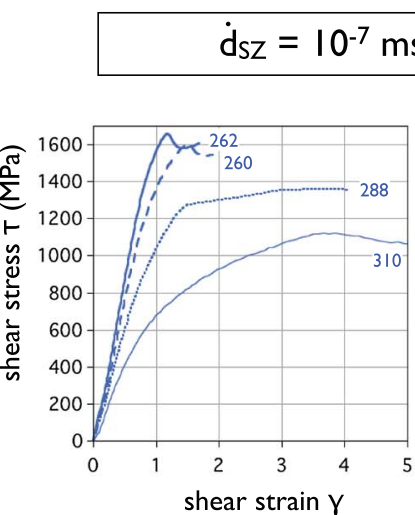

(a)

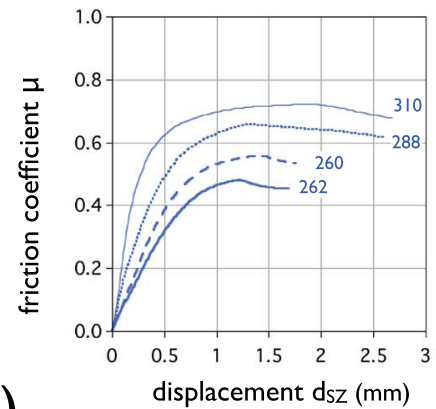

(b)

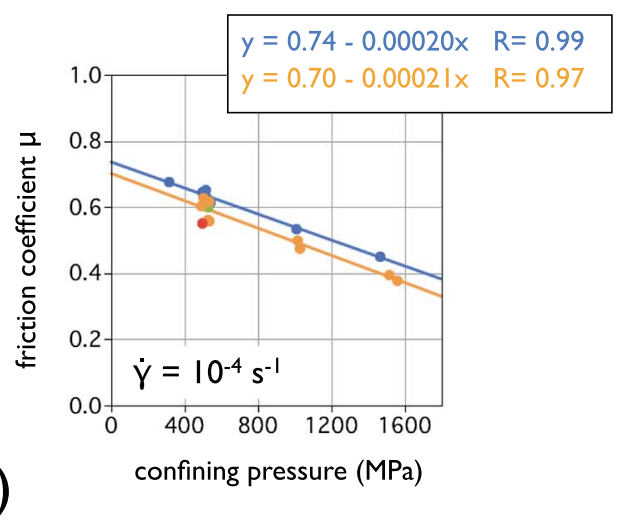

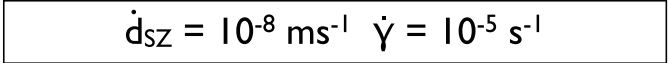
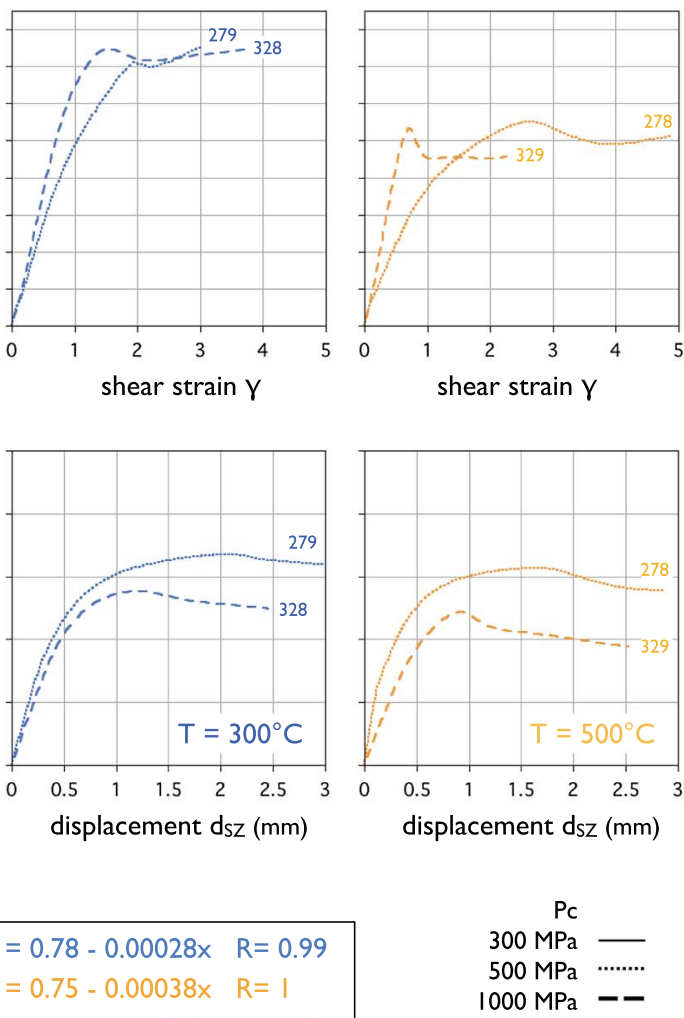

$1500 \mathrm{MPa}=$

$\mathrm{T}$

$300^{\circ} \mathrm{C}$

$400^{\circ} \mathrm{C}$

$500^{\circ} \mathrm{C}$

$600^{\circ} \mathrm{C}$

Figure 8. Strength expressed by shear stress or friction coefficient. (a) Influence of confining pressure on shear stress $\tau$ for two strain rates and two temperatures: $\dot{\gamma}=10^{-4} \mathrm{~s}^{-1}$ and $10^{-5} \mathrm{~s}^{-1}$ and $T=300^{\circ} \mathrm{C}$ and $500^{\circ} \mathrm{C}$. (b) Influence of confining pressure on friction coefficient $\mu$ for same two strain rates and temperatures as Figure 8a. (c) Friction coefficient as function of confining pressure $P_{c}$ for same two strain rates as Figures $8 \mathrm{a}$ and $8 \mathrm{~b}$. $\mu=\tau / \sigma_{\mathrm{n}}=$ friction coefficient, $\tau=$ shear stress, $\sigma_{\mathrm{n}}=$ stress normal to shear zone boundary, $\dot{d}_{\mathrm{sz}}=$ displacement rate parallel to shear zone boundary, $\dot{\gamma}=$ shear strain rate. Temperature is coded by color; see inset on lower right. For Figures $8 \mathrm{a}$ and $8 \mathrm{~b}$ confining pressure is indicated by line thickness. Note: Increasing $P_{c}$ increases $\tau$ but decreases $\mu$. At lower $\dot{\gamma}$, the effect of $P_{c}$ on $\tau$ is less pronounced, while the effect of $T$ on $\mu$ is more pronounced.

the activation energy with a decrease in strain rate (Figure 7b). As we conducted constant displacement rate experiments (rather than constant load experiments), the value of the stress exponent, $n$, is convolved into the estimation of the activation energy, and hence, the determination of $Q$ is not rigorous and subject to large errors [cf. Twiss and Moores, 2007, pp. 485-486].

\subsection{Influence of Confining Pressure}

Experiments performed at $T=300^{\circ} \mathrm{C}$ and shear strain rate, $\gamma^{\circ} \sim 10^{-4} \mathrm{~s}^{-1}$ show that the peak shear stress of the samples, i.e., the strength of the fault rock, increases with increasing confining pressure and occurs at lower shear strains (Figure 8a). The increase in peak shear stress is more pronounced between 500 and $1000 \mathrm{MPa}$ 
(a)

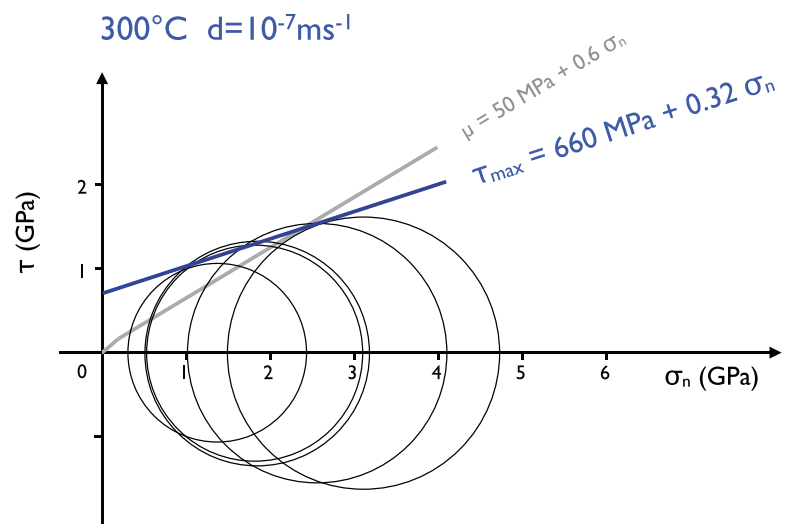

\begin{tabular}{|c|c|c|}
\hline sample & $P_{c}$ & $\Delta \sigma$ \\
\hline 310 & 311 & 1337 \\
\hline 291 & 519 & 1738 \\
\hline 288 & 538 & 1745 \\
\hline 260 & 1007 & 2336 \\
\hline 262 & 1463 & 2466 \\
\hline
\end{tabular}

(b)

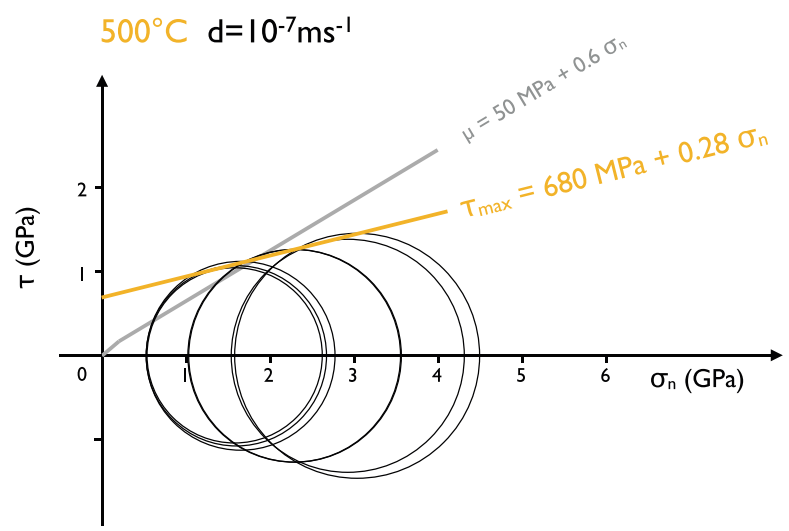

\begin{tabular}{|c|c|c|}
\hline sample & Pc & $\Delta \sigma$ \\
\hline 290 & 532 & 1327 \\
\hline 289 & 527 & 1354 \\
\hline 253 & 530 & 1732 \\
\hline 256 & 1023 & 1864 \\
\hline 255 & 1011 & 2037 \\
\hline 266 & 1514 & 1991 \\
\hline 263 & 1554 & 1897 \\
\hline
\end{tabular}

Figure 9. Mohr circle presentation of experimental results. (a) Experimental temperature $=300^{\circ} \mathrm{C}$, linear fit yields $\tau_{\max }=660 \mathrm{MPa}+0.32 \sigma_{\mathrm{n}}$. (b) Experimental temperature $=500^{\circ} \mathrm{C}$, linear fit yields $\tau_{\max }=680 \mathrm{MPa}+0.28 \sigma_{\mathrm{n}}$. Gray line $=$ Byerlee's rule for $\Delta \sigma=2 \cdot \tau_{\max }$. Confining pressure $P_{c}$ is used as $\sigma_{3}$.

confining pressure $(\Delta \tau \sim 250 \mathrm{MPa})$, whereas only a small increase $(\sim 75 \mathrm{MPa})$ takes place between 1000 and $1500 \mathrm{MPa}$ confining pressure.

In contrast, the friction coefficient, $\mu$, of the fault rock decreases with increasing confining pressure (Figure 8b). This dependence is more clearly shown when the friction coefficient at peak stress, $\mu_{\max }\left(=\tau_{\max } / \sigma_{\mathrm{n}}\right)$ is plotted versus confining pressure (Figure 8c). Using a linear fit to the data, the friction coefficient, $\mu$, decreases by $0.02-0.04$ for every $100 \mathrm{MPa}$ increase in confining pressure, and this dependence is more pronounced at slower strain rates and higher temperatures. In other words, in terms of the friction coefficient the samples become "weaker" (i.e., $\mu$ decreases), but in terms of the flow stress the samples become "stronger" (i.e., $\tau$ increases) with increasing confining pressure.

Two sets of experiments performed at a displacement rate of $10^{-7} \mathrm{~m} \mathrm{~s}^{-1}$ and at temperatures of $300^{\circ} \mathrm{C}$ and $500^{\circ} \mathrm{C}$ are plotted as Mohr diagrams (Figure 9). The confining pressure is plotted as $\sigma_{3}$ and the differential stress $\Delta \sigma$ as the diameter of the Mohr circle. For shear zones that are oriented at $45^{\circ}$ with respect to $\sigma_{1}, \tau$ (on the failure plane) corresponds to the radius of the Mohr circle, and $\sigma_{\mathrm{n}}$ (on the failure plane) corresponds to $\sigma_{\text {mean }}$. The failure envelopes $\left(\tau=C_{0}+f \cdot \sigma_{n}\right)$ are not drawn as tangent lines to the Mohr circles but are fitted through $\tau_{\max }$ corresponding to the $45^{\circ}$ orientation of the failure plane, i.e., shear zone. For both experiments, the line fit yields a high cohesion, $C_{0}$ of $660-680 \mathrm{MPa}$ and a low normal stress dependence with an angle of internal friction of $14^{\circ}-18^{\circ}(f=0.28-0.32$, equation (1)).

\section{Microstructural Analysis}

In order to identify the physical processes responsible for the observed rheological behavior, micro- and nanostructural investigations of the experimental fault rocks were carried out. 
$\mathrm{T}=300^{\circ} \mathrm{C} 400^{\circ} \mathrm{C} 500^{\circ} \mathrm{C} 600^{\circ} \mathrm{C}$

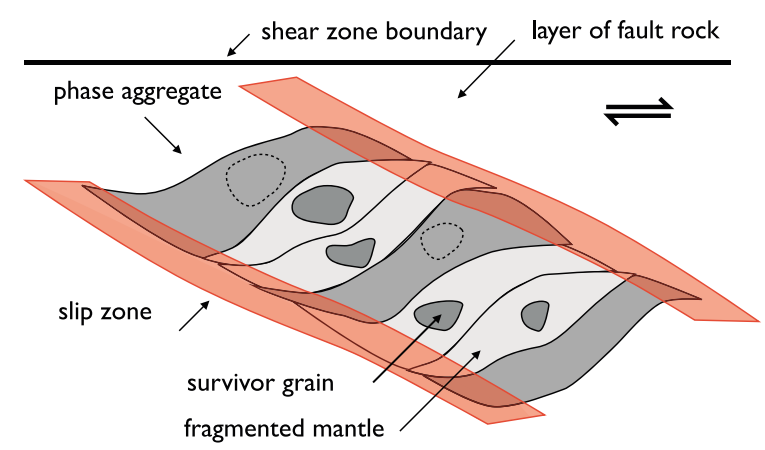

(a)

Figure 10. Microstructural development of shear zones. (a) Schematic of microstructure elements. Note: phase aggregate comprises survivor grains and fragmented mantle: $V_{a}=V_{s}+V_{\mathrm{fm}}$. (b) Decrease of volume fraction of survivor grains. $V_{s}$, $V_{a}=$ volume fraction of survivor grains and aggregates, respectively, $\mathrm{Qtz}=$ quartz, $\mathrm{Plg}=$ plagioclase, and $\mathrm{Kfs}=\mathrm{K}$-feldspar.

\subsection{Sample Preparation and Image Acquisition}

After the experiment, samples are vacuum impregnated with a low viscosity epoxy and doubly polished thin sections $(\sim 30 \mu \mathrm{m}$ thick) parallel to the compression axis, $z$, and the displacement direction, $x$, are prepared (see Figure $2 \mathrm{~d}$ ). The samples are carbon coated and analyzed with field emission scanning electron microscopes (SEM) equipped with energy-dispersive spectrometers (EDS) (Philips XL 30 ESEM and FEI Nova Nano SEM 230) under 5-20 kV acceleration voltage at the ZMB Basel. At selected sites, transmission electron microscope (TEM) foils are prepared with a FEI NanoLab 600 FIB-SEM using a Gaion beam for focused ion beam (FIB) milling. TEM foils ( 50-100 nm thick) are analyzed in a FEI Technai 20 Field emission TEM with an EDS detector at $200 \mathrm{kV}$ acceleration voltage at Utrecht University. Cold cathodoluminescence $(\mathrm{CL})$ images are obtained using a Technosys $8200 \mathrm{Mkll}$ at a $20 \mathrm{kV}$ acceleration voltage. SEM-CL images are obtained using a Zeiss EVO 50 SEM with a Gatan Mono CL 3 system at $20 \mathrm{kV}$ acceleration voltage at Bern University.

\subsection{Image Analysis Methods}

In this paper, the micrographs of the deformed fault rock are always oriented with the displacement direction horizontal (Figure 2d). Images are analyzed with a dextral sense of shear, and angles are measured counterclockwise from $0^{\circ}$ (positive $x$ direction) to $180^{\circ}$. Typically, deformation localizes near one of the forcing blocksample interfaces and is transferred through the sample to the symmetric position on the other side of the shear zone [see Pec et al., 2012b, Figures 4 and 6]. To evaluate the microstructural development, central areas of the shear zones are analyzed where slip is transferred from one forcing block to the other (Figure $2 \mathrm{~d}$ ). The width of the analyzed areas is $\sim 1700 \mu$ m (i.e., $\sim 18 \%$ of the starting length of the shear zone); the height is between $\sim 450$ and $\sim 800 \mu \mathrm{m}$ covering the entire thickness of the shear zones.

First, the images are segmented into the five constituent mineral phases. On SEM-backscattered electron (BSE) micrographs (atomic number contrast), the phases can be distinguished on account of their brightness, in order of increasing brightness: quartz (Qtz), plagioclase (Plg), white mica (Wm), potassium feldspar (Kfs), and biotite (Bt). Using a combination of SEM-BSE and CL images, the phases were separated via gray level slicing and thresholding using ImageSXM (http://www.liv.ac.uk/ sdb/lmageSXM/) and Photoshop ${ }^{\mathrm{Tm}}$. For methods of analysis, see Heilbronner and Barrett [2014].

Next, slip zones are identified, and each of the mineral phases is further segmented into so-called survivor grains and fragmented mantle by manual tracing (Figure 10a). Survivor grains are grains which are easily identifiable at a magnification of $100 \times(1 \mathrm{px}=0.833 \mu \mathrm{m})$, and the fragmented mantle is defined as the finely crushed material with a grain size $<1 \mu \mathrm{m}$ that surrounds the survivor grains. In the fragmented mantles, individual grains cannot be distinguished but porosity can still be observed at this magnification. 
The following analyses were carried out:

1. Using the bitmaps of the aggregates, the volume fraction of each of the mineral phases is determined.

$$
V_{\text {phase }} / V_{\text {total }}=A_{\text {phase }} / A_{\text {total }}
$$

where $V_{\text {phase }}=$ volume and $A_{\text {phase }}=$ area of a given phase, and $V_{\text {total }}=$ total volume and $A_{\text {total }}=$ total area of image. For the stereological derivations, see Underwood [1970].

Using separate bitmaps of survivor grains and fragmented mantles, the area fraction of the survivor grains $\left(A_{s}\right)$ and of the fragmented mantles $\left(A_{\mathrm{fm}}\right)$ are determined separately. From this, the volume fractions are calculated analogous to equation (7). The fraction of survivor grains per phase is taken as a measure for comminution and is calculated by the following equation:

$$
V_{s} / V_{a}=A_{s} / A_{a}=A_{s} /\left(A_{s}+A_{\mathrm{fm}}\right)
$$

where the subscript "a" denotes aggregates which are the combined areas or volumes of survivor grains and fragmented mantle (Figure 10a) [Pec et al., 2012a; Boutareaud et al., 2012]. Complementary to the decrease of survivor grains the increase of the fractional volume of fragmented mantle is another measure for comminution.

Slip zones are recognized by a distinct $\mathrm{CL}$ signal and by showing absolutely no porosity up to a magnification of $20000 \times$ in a SEM ( 1 pixel $=4 \mathrm{~nm}$ ). Slip zones are also recognized as strips with regularly spaced, small unloading cracks (occurring preferentially in plastically deformed material unable to recuperate elastic strain upon unloading). The slip zones are traced manually, and their fractional volume is determined as above (equation (8)).

The shape and connectivity of the slip zones is quantified using the autocorrelation function (ACF); three adjacent ACFs spanning the width of the shear zone are averaged to yield a representative results for the center part of the slip zone. For ACF technique, see Heilbronner and Barrett [2014, pp. 389-409].

The volume fractions of the individual mineral phases within the slip zones are obtained by intersecting bitmaps of the manually traced slip zones with phase maps (bitmaps) of the individual aggregates.

Grain size is measured as the diameter of the area equivalent circle of a given 2-D shape. From measured histograms of 2-D gran size, the distribution of 3-D grains is calculated using stripstar [see Heilbronner and Barrett, 2014, pp. 207-215].

\subsection{Microstructural Observations}

\subsubsection{Comminution in the Shear Zone}

The ratio of survivor grains to fragmented mantle $\left(V_{s} / V_{a}\right)$ is a good measure for comminution; measured as a percentage, it may range from $100 \%$ (entire aggregate formed by survivor grains) to $0 \%$ (entire aggregate formed by fragmented mantle). In the samples analyzed here, the values rapidly decrease already at low shear strain $(1<\gamma<2)$ and then continue decreasing at a slower rate up to the highest explored shear strains $(\gamma \geq 4)$ (Figure 10b,). Comminution occurs during the entire range of shear strains explored here, with quartz always fracturing the least and both feldspars fracturing the most.

Fitting exponential decay functions to the $V_{s} / V_{a}$ ratios, we observe a weak but systematic dependence on temperature for quartz, indicating that the $V_{s} / V_{a}$ ratio of quartz deformed at $500^{\circ} \mathrm{C}$ is about $10 \%$ higher than if deformed at $300^{\circ} \mathrm{C}$ (Figure 10b). No clear dependence on temperature can be detected in any of the feldspars due to the small amount of survivor grains at shear strains $\gamma>2.5$. Note that as we conducted constant displacement rate experiments, temperature and stress do not vary independently; lower temperature experiments support higher stresses (Figure 4). In other words, the temperature dependence also implies a stress dependence.

\subsubsection{Development of Slip Zones}

At a shear strain of $\gamma \sim 1.5$, incipient slip zones can be detected as nonporous, cohesive zones where small unloading cracks concentrate. First, they form as isolated thin patches at high stress/high strain sites adjacent to bigger quartz grains and micas, usually in a $C^{\prime}$ orientation, where extremely fine grained feldspar material forming the fragmented mantle is abundant [Pec et al., 2012a]. With increasing finite strain, they become interconnected and form an anastomozing network. The interconnectivity of the layers increases with increasing temperature and finite strain (Figure 11). 

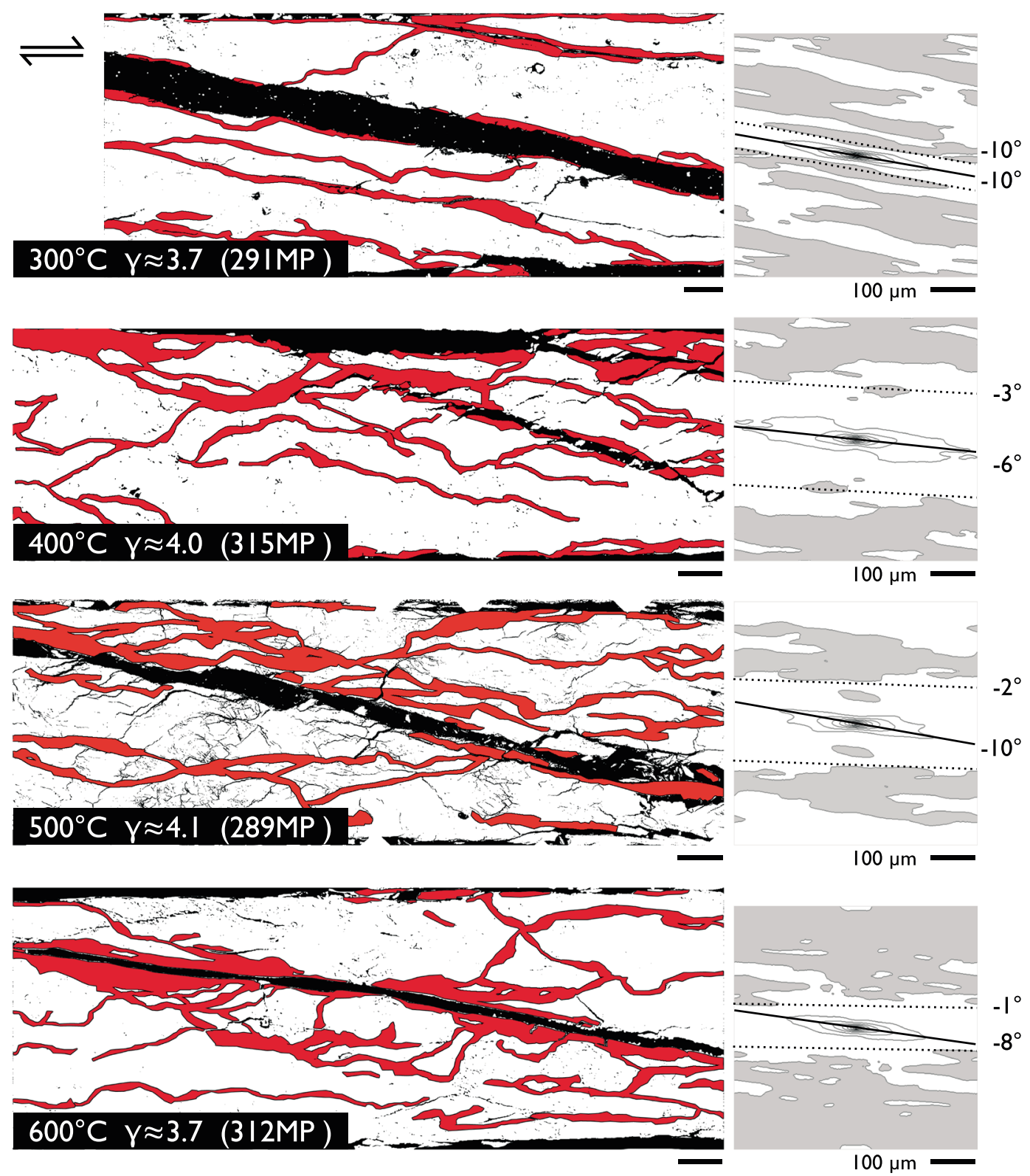

Figure 11. Development of slip zone geometry. Left: tracing of slip zones from four high strain experiments at different temperatures: red slip zones, black: unloading cracks. Scale bars are $100 \mu \mathrm{m}$. Right: corresponding bulk ACF obtained by averaging three ACFs. Contours at intervals of 0.1 of $A C F_{\max }$, gray shading $=\mathrm{ACF}<0.1 \cdot \mathrm{ACF}_{\max }$. Solid lines: high (short range) correlation indicating $C^{\prime}$ orientation of slip zones, dashed lines: background (long range) correlation indicating bulk structure in $\mathrm{C}$ orientation.

The ACFs reveal a temperature-dependent development of the slip zones. At a bulk shear strain of $\gamma \sim 4$, the most prominent slip zones are inclined in a stable $C^{\prime}$ orientation (short range correlation between $-6^{\circ}$ and $-10^{\circ}$ ). With increasing temperature, however, slip zones increasingly develop in the $\mathrm{S}$ and $\mathrm{C}$ orientation, causing the anisotropy of the bulk fabric to intensify and to align itself with the shear zone boundary as evidenced by the background correlation which rotates from $-10^{\circ}$ at $300^{\circ} \mathrm{C}$ into an approximately horizontal one at $600^{\circ} \mathrm{C}$ (Figure 11 ).

Estimates of the shear strain, $\gamma_{\mathrm{sz}}$ accommodated in a given slip zone yields $\left(\sim 5<\gamma_{\mathrm{sz}}<10\right)$ at bulk shear strain of $\gamma \sim 2$, and even higher $\left(\gamma_{s z}>20\right)$ at bulk shear strains of $\gamma \sim 4$, implying an increasing strain partitioning into the slip zones with a shear strain enhancement of 2.5 to $>5$ times. However, markers to 


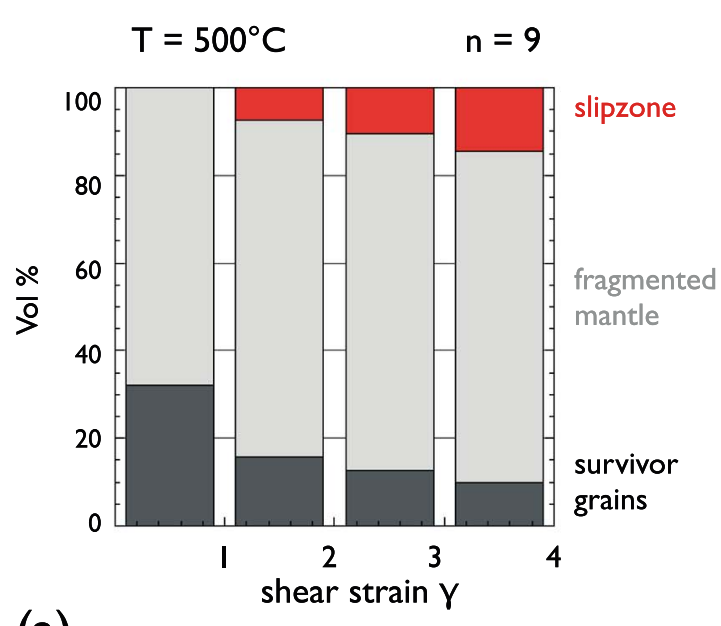

(a)

vol $\%$

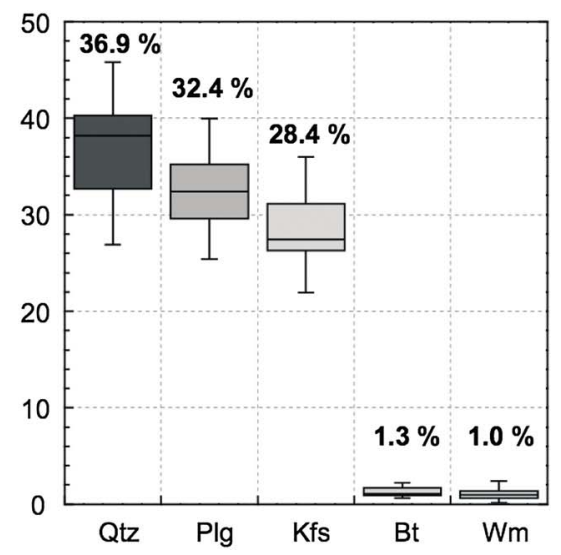

(c)

(d)

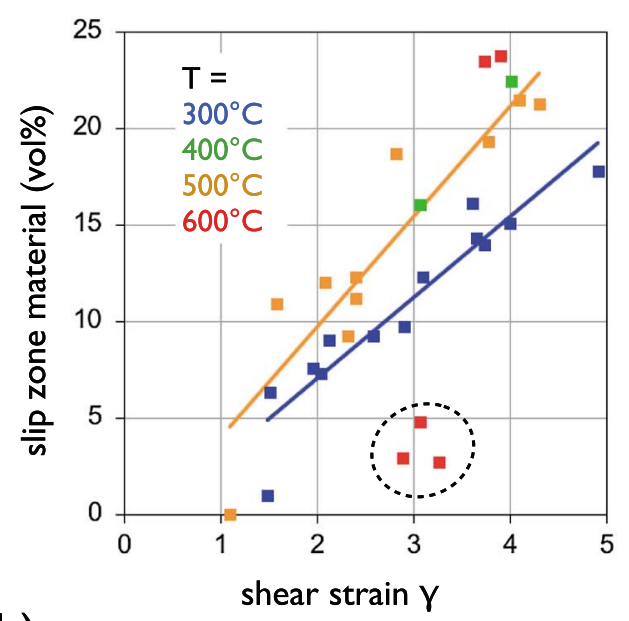

(b)

vol \%

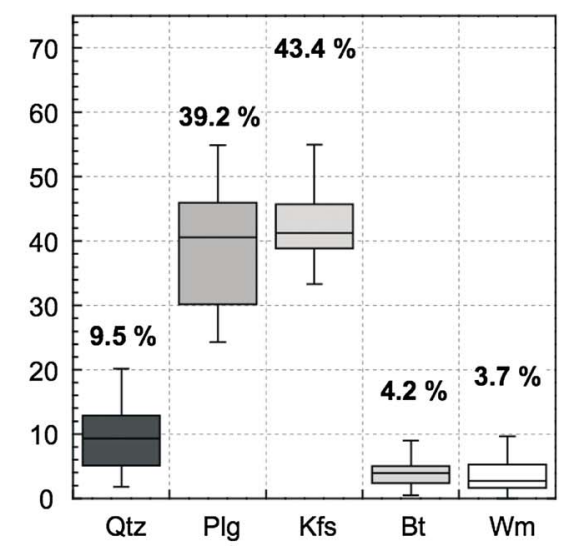

Figure 12. Slip zones. (a) Buildup of fragmented mantle and slip zone material. (b) Increase of slip zone material with shear strain for different temperatures. Dashed circle shows experiments performed at slowest strain rates. See text for details. (c) Composition of starting material. (d) Composition of material within slip zones. Qtz = quartz, Plg = plagioclase, $\mathrm{Kfs}=\mathrm{K}$-feldspar, $\mathrm{Bt}=$ biotite, and $\mathrm{Wm}=$ white mica.

measure offset are hard to detect at high bulk shear strains, and the accuracy of the measurements drops significantly.

With few exceptions, the total volume of the slip zones increases steadily with increasing bulk finite strain and increasing temperature (Figures $12 \mathrm{a}$ and $12 \mathrm{~b}$ ) - exceptions are samples deformed at $600^{\circ} \mathrm{C}$ and shear strain rates of $\sim 10^{-5} \mathrm{~s}^{-1}$ and will be discussed later. A weak but systematic dependence of the amount of slip zones can further be seen with confining pressure and strain rate. The slip zones are more abundant at higher confining pressures and faster strain rates (i.e., higher stresses).

\subsubsection{Shear Zone and Slip Zone Mineralogy}

The composition of the slip zones is distinct from the composition of the starting material. The material has a chemical composition similar to feldspars but shows a variable amount of all three alkalis ( $\mathrm{Na}, \mathrm{Ca}$, and $\mathrm{K})$ [Pec et al., 2012a, 2012b]. In 28 experiments with slip zones, the bulk fault rock composition is as follows: $\mathrm{Qtz}=36.9 \%, \mathrm{Plg}=32.4 \%, \mathrm{Kfs}=28.4 \%, \mathrm{Bt}=1.3 \%$, and $\mathrm{Wm}=1 \%$. In the slip zones, the Qtz content drops to $\sim 9.5 \%$, while feldspar (Plg and $\mathrm{Kfs}$ ) and mica (Bt and $\mathrm{Wm}$ ) contents increase significantly (Figures $12 \mathrm{c}$ and $12 \mathrm{~d}$ ). The ratio between the content of Plg and $\mathrm{Kfs}$ and that of Bt and $\mathrm{Wm}$ is $\sim 1: 1$ in both bulk samples 

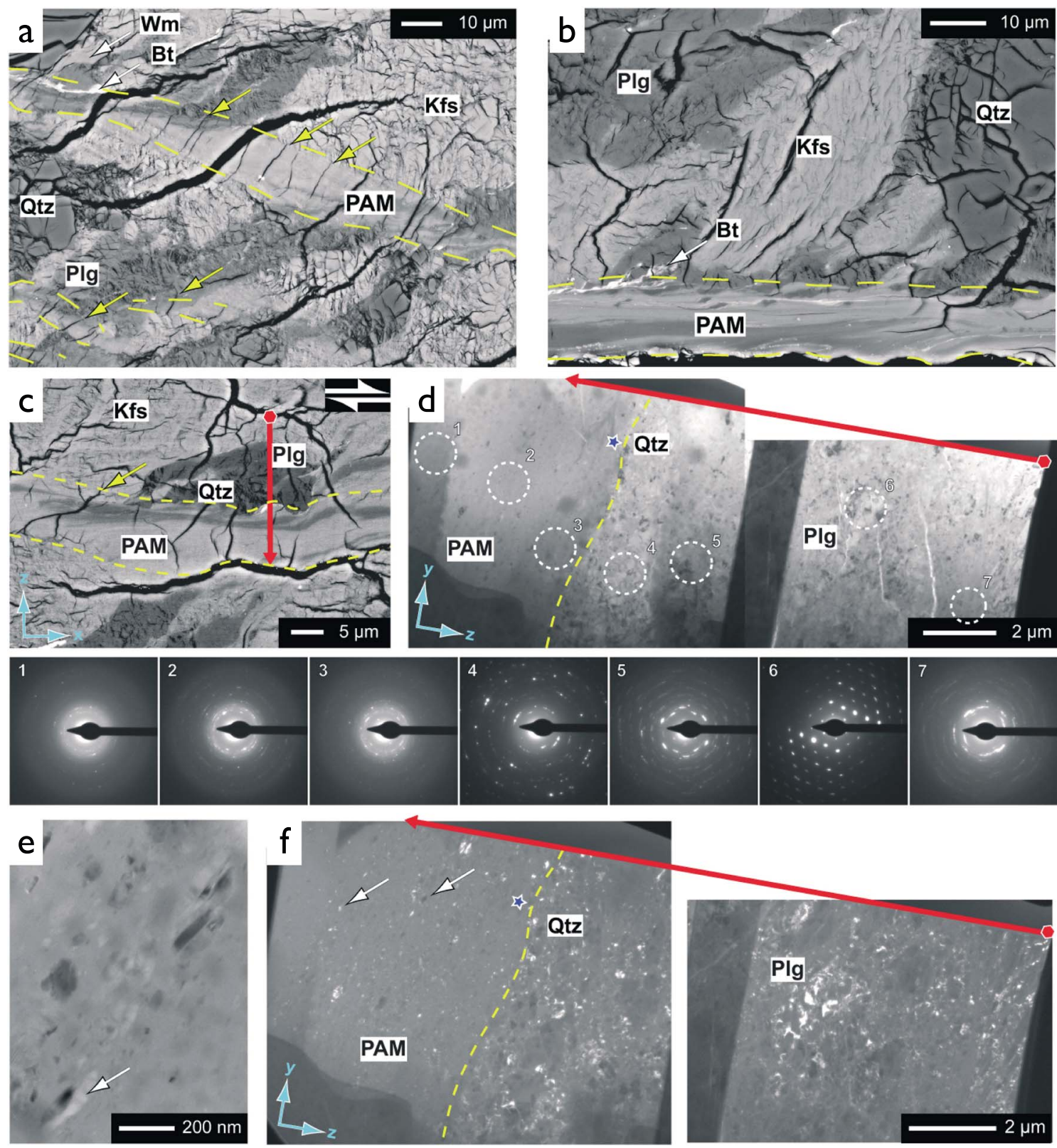

Figure 13. Partial amorphization of fault rock material in low strain shear zones. (a and b) SEM-BSE $z$ contrast image, PAM = partially amorphous material, yellow dashed line = slip zone boundary, yellow arrows point to unloading cracks indicating that PAM is cohesive (see text). (c) SEM-BSE z-contrast image, red line = trace of FIB foil shown in Figures 13d and 13f. (d) TEM-bright field image of FIB foil prepared along red transect shown in Figure 13c, numbered circles indicate sites of selected area electron diffraction (SAED), patterns shown below. Note the progressive change in SAED from individual diffracting points to amorphous halo. (e) High magnification TEM-bright field image of PAM. Notice elongation and SPO of individual crystalline particles (white arrow) and bent crystal planes (shown by changing contrast from white to black within grains). (f) TEM-dark field image of Figure 13d. More than $90 \%$ of the PAM appears homogeneously gray, i.e., is amorphous to the TEM beam; white arrows point to small crystalline grains. Light blue arrows: $x=$ transport direction, $y=$ transverse direction, $z=$ normal to shear plane, Qtz $=$ quartz, Plg $=$ plagioclase, and Kfs $=\mathrm{K}$-feldspar.

and in slip zones. Note that $\mathrm{Kfs}$, Plg, Bt, and $\mathrm{Wm}$ in the slip zones occur as partly amorphous material derived from their crystalline parents by comminution, as described below.

\subsubsection{Microstructural Evolution in Slip Zones With Increasing Strain}

4.3.4.1. Low Strain Slip Zones (Peak Strength Microstructures)

Incipient slip zones develop predominantly from extremely fine grained feldspar mantles (grain size, $d_{\text {equ }}<100 \mathrm{~nm}$ ), with flow structures, often adjacent to micas and quartz aggregates (Figures 13a and 13b). Locally, up to $\sim 90 \%$ of the slip zone material showed no contrast changes in both dark field and bright field 


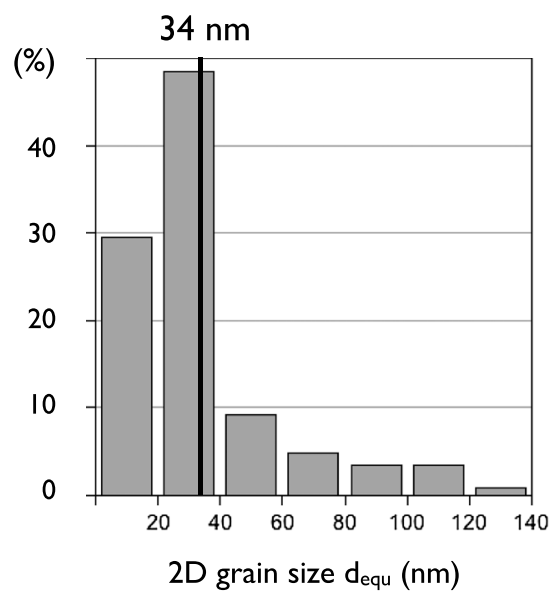

(a)

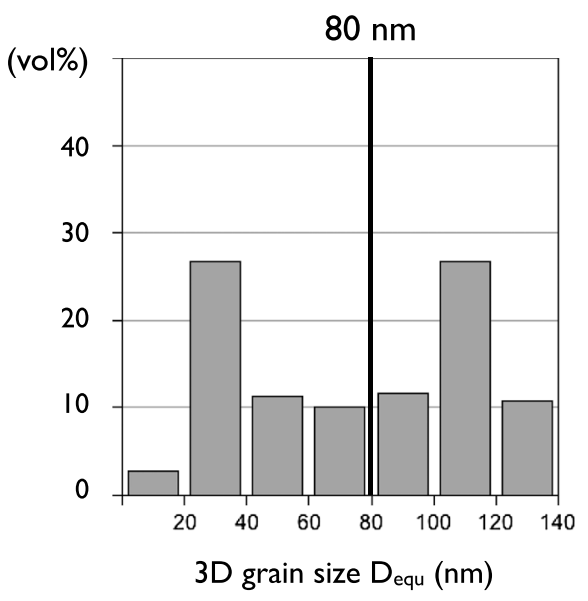

(b)

Figure 14. Grain size of crystalline particles in partially amorphous material (PAM). (a) Number-weighted histogram of equivalent diameters of cross-sectional areas, $d_{\text {equ }}$ (b) Corresponding volume-weighted histogram of equivalent diameters of derived spheres, $D_{\text {equ }}$. Mean values are indicated.

TEM images during tilting, indicating a high fraction of amorphous material. The smallest crystalline fragments embedded in the amorphous matrix, which can be detected in the TEM, have a grain size of $\sim 8 \mathrm{~nm}$ (Figures 13d-13f). Crystalline grains are angular, often elongated (mean axial ratio, b/a $\sim 0.6$ ) and show bent crystal planes (Figure 13e). Locally, a strong shape preferred orientation (SPO) is developed and no porosity can be resolved in a TEM. Selected area diffraction patterns (SADP) show weak spots and incomplete diffraction rings, indicating that crystal domains are rotated with respect to one another (Figure 13d), as well as a broader band of diffuse intensity consistent with poorly crystalline to amorphous material [Viti, 2011]. The broader band of diffuse intensity is more pronounced in regions where a higher strain was accommodated. In the following, we will refer to this type of slip zone material as "nanocrystalline to partly amorphous material" (PAM).

The mean 2-D grain size of all fragments is $d_{\text {equ }}=34 \mathrm{~nm}$, and the mean 3-D grain size is $D_{\text {equ }}=80 \mathrm{~nm}$ (Figure 14). Note, however, that the distribution of $D_{\text {equ }}$ has not a clear mode, possibly indicating a fractal grain size distribution.

\subsubsection{High Strain Slip Zones (After Steady State Deformation)}

After peak strength, the slip zones typically continue to accumulate strain and progressively change their microstructure. Turbulent flow structures, very thin lamination, and a heterogeneous chemical composition develop (Figures 15a-15d), occasionally showing intrusive relationships with the surrounding crystalline aggregates and forming "injection veins" [Pec et al., 2012b]. On the TEM scale these layers are almost completely amorphous as shown by rings of diffuse intensity in SADP's (Figures 15e-15h) with very few diffracting crystals (grain size $\sim 6 \mathrm{~nm}, d$-spacing $\sim 1 \mathrm{~nm}$ ). We will refer to this type of slip zone material as "amorphous material" (AM). The feldspar-derived PAM within the high strain slip zones has fewer diffracting grains compared to lower strain PAM (compare SADP and TEM-bright field (BF) images) and locally only a halo of diffuse intensity without any bright spots can be detected (compare Figures 13 and 15). Furthermore, within the AM lenses of PAM, polycrystalline Qtz as well as single Qtz grains can be observed (Figure 15g).

These microstructures are observed in all slip zones of high strain experiments, irrespective of the temperature, confining pressure, or displacement rate. In some experiments conducted at $300^{\circ} \mathrm{C}$, the slip zone material locally forms very small bubbles $\left(d_{\text {equ }}=15 \mathrm{~nm}-1 \mu \mathrm{m}\right.$, Figure $15 \mathrm{~d}$ ) which are stretched and follow the local flow pattern [Pec et al., 2012b]. These bubbles occur exclusively along slip zones in C' orientation. In high strain samples, both, the AM and the PAM layers, are often discordantly cut by principal unloading cracks (Figure 11) indicating that they must have formed before quenching and cannot be the result of the unloading procedure. 

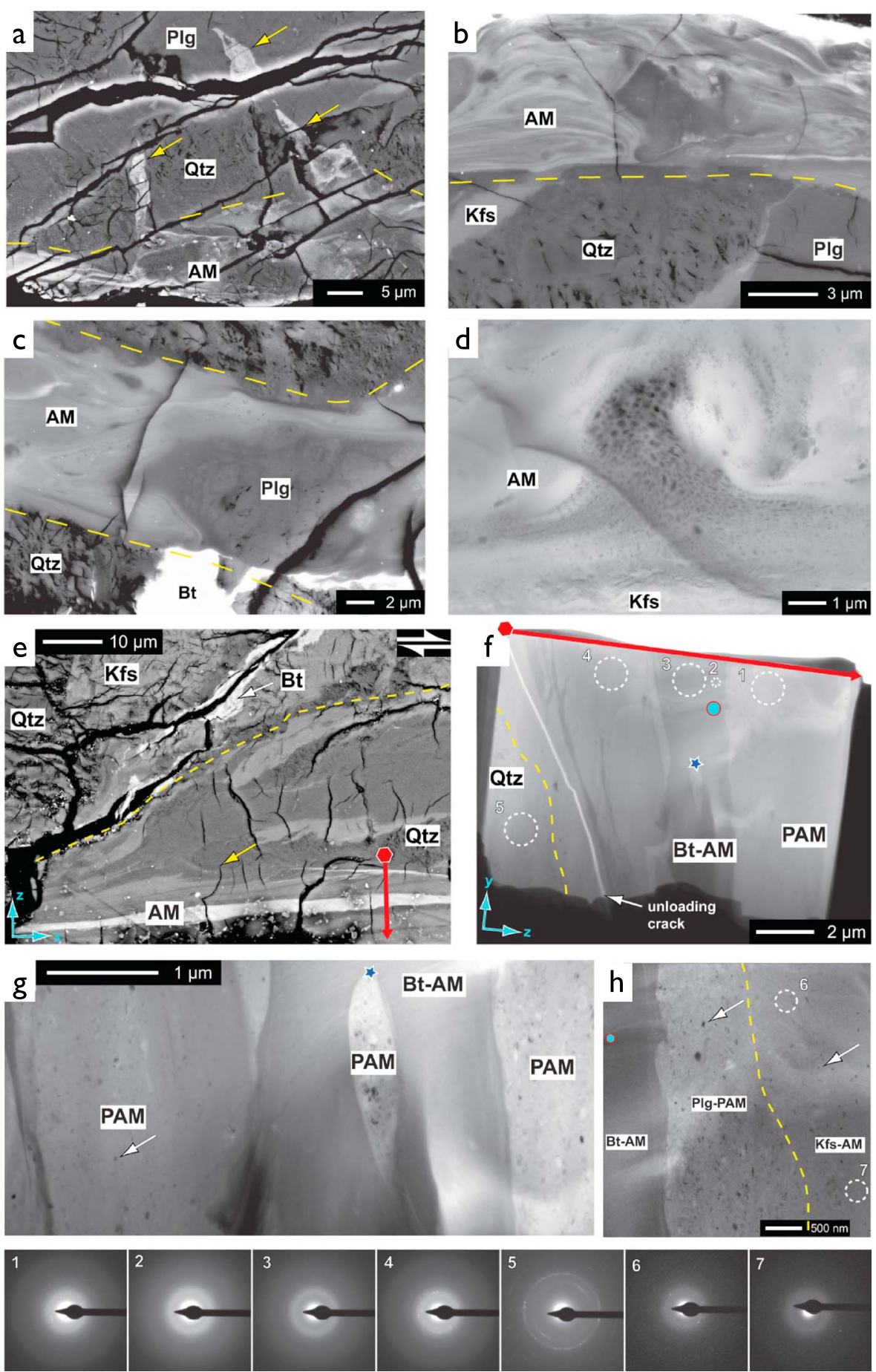

Figure 15. Amorphization of fault rock material in high strain shear zones. PAM = partially amorphous material, $\mathrm{AM}=$ amorphous material; yellow stippled line = slip zone boundary. (a-e) SEM-BSE $z$ contrast images. (f-h) TEM-BF images. (Figure 15a) Injection veins of AM in high strain shear zone. (Figure 15b) Flow structures in AM in high strain sample-sample failed abruptly. (Figure 15c) Flow structures in AM in high strain sample-sample did not fail abruptly. (Figure 15d) Bubbles in the K-feldspar derived AM. (Figure 15e) Slip zone in C orientation. Yellow arrow points to unloading cracks, red line = trace of FIB foil shown in Figure 15f. (Figure 15f) FIB foil prepared along red transects shown in Figure 15e; numbered circles indicate sites of selected area electron diffraction patterns shown below. Note few individual diffracting points and a well-developed amorphous halo. (Figure 15g) PAM fragment embayed in AM. Notice few individual crystalline particles (white arrow) and their progressive disappearance toward the AM. (Figure 15h) Plg-derived PAM surrounded by AM. Arrows point to larger crystalline grains. Light blue arrows: $x=$ transport direction, $y=$ transverse direction, $z=$ normal to shear plane, $\mathrm{Qtz}=$ quartz, $\mathrm{Plg}=$ plagioclase, $\mathrm{Kfs}=\mathrm{K}$-feldspar, $\mathrm{Bt}=$ biotite, $\mathrm{Wm}=$ white mica. 


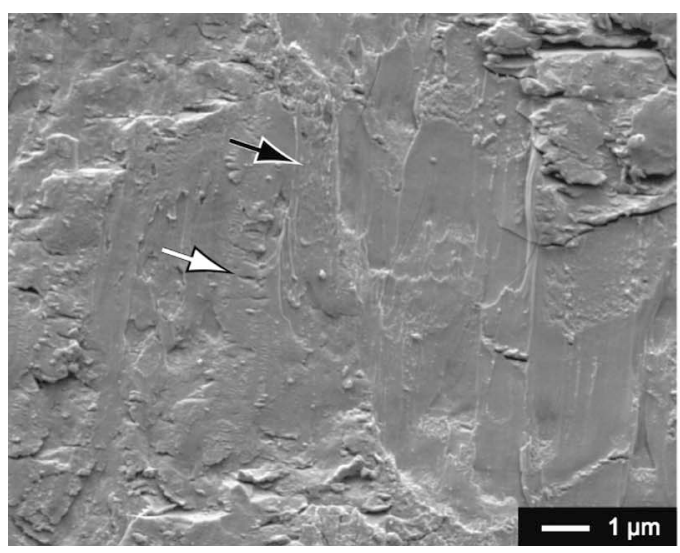

(a)

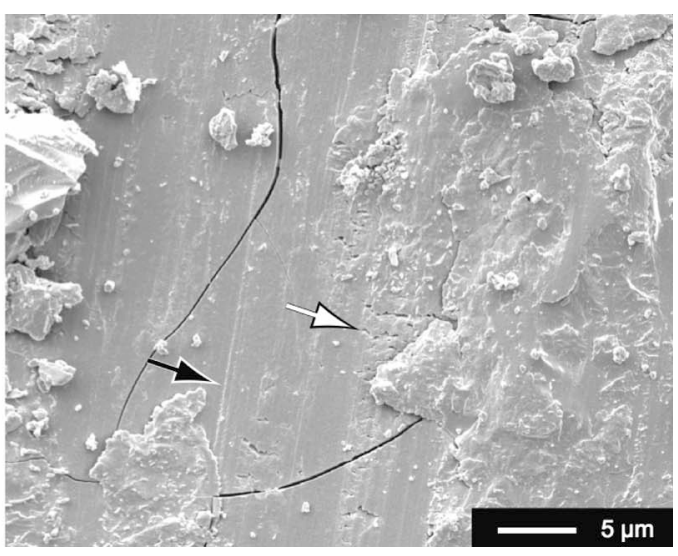

(b)

Figure 16. Surface of slip zones. SEM images of surfaces revealed along unloading cracks. (a) Sample deformed at $T=400^{\circ} \mathrm{C}$ and $P_{c} \approx 500$ (MP306). (b) Sample deformed at $T=500^{\circ} \mathrm{C}$ and $P_{C} \approx 500$ (MP278). White arrows point to closely spaced unloading cracks which are typical of the permanently deformed PAM and AM (compare Figures 13 and 15); black arrows point to striations/slickenslides which form parallel to the displacement direction.

\subsubsection{High Strain Slip Zones (After Abrupt Failure)}

Samples deformed at $T=300^{\circ} \mathrm{C}, P_{c} \approx 500 \mathrm{MPa}$ and shear strain rates of $10^{-3} \mathrm{~s}^{-1}$ reach high shear stresses $(\tau \approx 1.4 \mathrm{GPa})$ and fail abruptly around peak strength. In slip zones of such samples, bubbles develop in the PAM/AM. Preferential sites where bubbles appear are within micas adjacent to larger quartz survivor grains, i.e., where the material is subjected to high local stresses. The bubble trains can be usually followed only over short distances $(\sim 10 \mu \mathrm{m})$ and show turbulent flow structures. Otherwise, the slip zone microstructures are very similar to those formed in samples which did not fail abruptly (compare Figures $15 \mathrm{~b}$ and $15 \mathrm{c}$ ).

\subsubsection{Observations on the Surface of Slip Zones}

Three samples were separated along a well-developed, principal unloading crack in the $C^{\prime}$ orientation. The broken surfaces of these samples were gold coated (thickness $\sim 20 \mathrm{~nm}$ ) and analyzed in the SEM with secondary electrons without any further preparation.

The surface of the unloading crack shows well-developed striations in both $400^{\circ} \mathrm{C}$ and $500^{\circ} \mathrm{C}$ experiments (Figure 16). Stringers of PAM and AM with regularly spaced unloading cracks can be observed. These cracks form in response to the unloading of permanently deformed materials, while the surrounding material recovers elastically, as described earlier.

\subsubsection{Samples Deformed at $600^{\circ} \mathrm{C}$ and Slow Strain Rates}

A notable exception to the general microstructural trend described above is samples deformed at $600^{\circ} \mathrm{C}$, slow shear strain rates $\left(10^{-5} \mathrm{~s}^{-1}\right)$, and confining pressures of 500 and $1000 \mathrm{MPa}$. These samples support the lowest shear stresses (580-860 MPa, Figure 4); all minerals fracture considerably less ( $>50 \%$ Qtz survivor grains, or, alternatively, the small grains are cemented rapidly) and have low amounts of slip zones ( $<5 \%)$ (Figure 12b) compared to all other explored conditions. In these experiments, very small pores are preserved between fine-grained clasts with interconnected grain boundaries, which are common in the whole sample (Figure 17).

\section{Discussion}

First, we will summarize the microstructural observations and inferred deformation processes. Then, we interpret the observed rheological behavior and discuss the importance of our results for natural deformation in fault zones.

\subsection{Deformation Mechanisms}

Based on our microstructural observations, we distinguish two different types of material in our sheared samples: (1) lens-shaped finely fractured phase aggregates and (2) slip zones consisting of partly amorphous (PAM) or amorphous (AM) material (Figure 10a). 

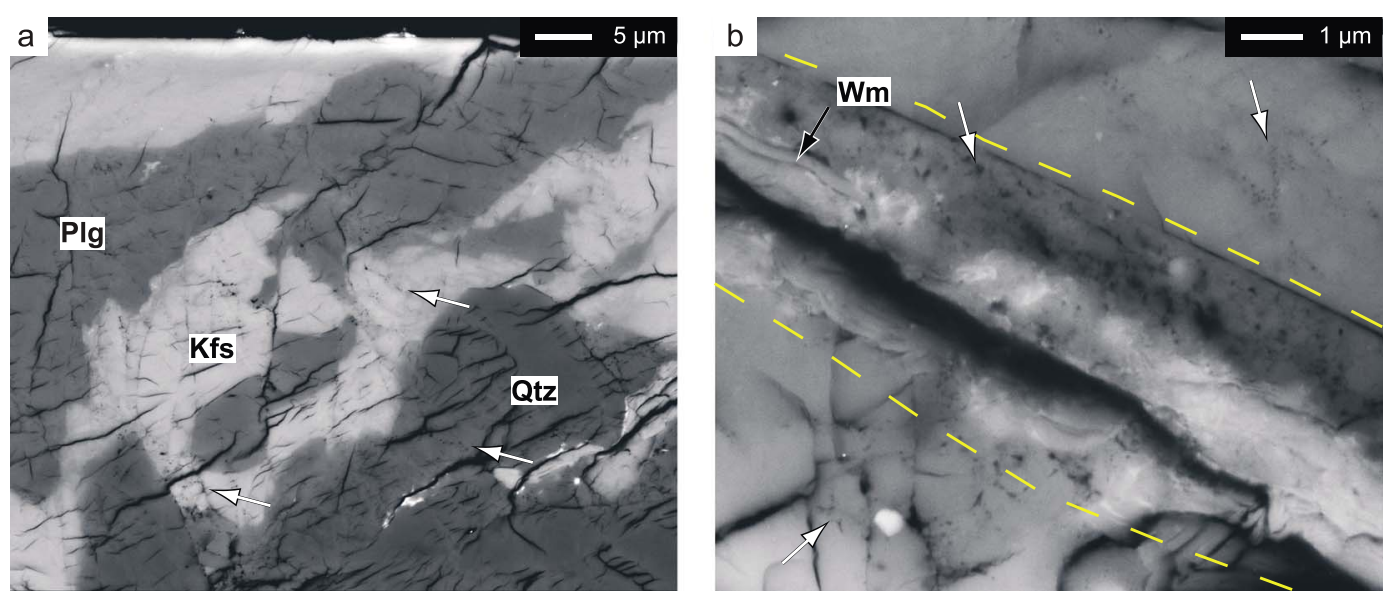

Figure 17. High-temperature, slow strain rate microstructures, SEM-BSE $z$ contrast images. Shear sense is dextral in all images. (a) Typical microstructure of healed fault rock, white arrows point to delicate porosity (sample deformed at $T=600^{\circ} \mathrm{C}, P_{c} \approx 500 \mathrm{MPa}, \dot{\gamma}=10^{-5}$ ). (b) Detail of slip zone with interconnected grain boundaries, white arrows point to delicate pores (sample deformed at $T=600^{\circ} \mathrm{C}, P_{\mathrm{C}} \approx 1000 \mathrm{MPa}, \dot{\gamma}=10^{-5}$ ).

\subsubsection{Phase Aggregates}

In all experiments, pervasive microfracturing of ever finer-grained material is observed in both feldspars and quartz. During early stages of deformation $(0<\gamma<1.5)$ compaction of the powder is achieved by short $(\sim 160 \mu \mathrm{m})$ and closely spaced $(10-50 \mu \mathrm{m}) R_{1}$ shears. Porosity is progressively reduced along these shears and extremely fine grained material $(<100 \mathrm{~nm})$ is produced [Pec et al., 2012a]. Both micas either develop kink bands or fracture. Micas exhibit a strong mechanical anisotropy [e.g., Kronenberg et al., 1990; Mares and Kronenberg, 1993]. Therefore, it depends on their crystallographic orientation with respect to the local kinematic framework, whether fracturing or kinking occurs. Quartz is comminuted the least and forms porphyroclasts at all scales. Furthermore, the amount of fragmented Qtz mantles tends to be smaller than that of feldspars (Figure 10b). Qtz does not have a well-developed cleavage and has strong covalent bonds; it appears to be the strongest phase at the employed experimental conditions. Feldspars are weaker than quartz because of their perfect cleavages and microporosity [Brace et al., 1972; Tajčmanová et al., 2012], which allow efficient fracturing [Yund et al., 1990]. Fracturing to very fine grains $(<0.1 \mu \mathrm{m})$ and cataclastic flow with a "fluidal" microstructure is commonly observed in feldspar aggregates at the P-T conditions employed in our study [e.g., Tullis and Yund, 1987]. Very few feldspar survivor grains can be observed after finite strains of $\sim 2$ (Figure 10b), and most of the feldspar material is transformed into fine-grained $(<100 \mathrm{~nm})$ fragmented mantle and PAM. The high shear stresses as observed in the mechanical record $(\tau \approx 0.6-1.4 \mathrm{GPa})$ are probably facilitated by the high abundance of quartz in the Verzasca powder $(\sim 37 \mathrm{vol} \%)$. Rigid inclusions in a softer matrix transfer load among each other, increasing the bulk strength of the rock in proportion to their volume (e.g., quartzcalcite mixtures) [Rybacki et al., 2003; Renner et al., 2007]. Both feldspars together represent more than $60 \mathrm{vol} \%$ of the sample and form a weaker interconnected matrix. Based on microstructural observations, it seems that granular flow (relative movement of grains) together with fracturing and probably also dissolution precipitation creep in the extremely fine grained material $(<100 \mathrm{~nm})$ accommodates deformation in the lenses. Clear microstructural evidence for dissolution precipitation creep (interconnected grains and fluid inclusion trails) is mostly found in slowly deformed $\left(\dot{\gamma} \approx 10^{-5} \mathrm{~s}^{-1}\right)$ experiments at $600^{\circ} \mathrm{C}$ (Figure 17), and in experiments performed under lower temperature conditions $\left(300^{\circ} \mathrm{C}\right.$ and $500^{\circ} \mathrm{C}$ ) with higher water content ( $\left.2 \mathrm{wt} \%\right)(\mathrm{M}$. Pec, unpublished data, 2011), and during longer duration experiments [Keulen et al., 2007, 2008].

\subsubsection{Slip Zones}

Pervasive comminution transforms larger survivor grains $\left(d_{\text {equ }}>100 \mu \mathrm{m}\right)$ into fine-grained $\left(d_{\text {equ }}<100 \mathrm{~nm}\right)$ fragmented mantles. Parts of the fragmented mantles are further transformed into a cohesive, nonporous, highly strained nanocrystalline (mean grain size, $d_{\text {equ }} \approx 34 \mathrm{~nm}$ ) to TEM-amorphous (up to $90 \%$ ) material (PAM) with abundant flow structures (Figures 13 and 15). This transformation occurs often next to quartz grains, which form high stress sites in the adjacent feldspar matrix. Similarly, favorably oriented micas (with 
their basal slip planes along the $C^{\prime}$ direction) tend to concentrate strain and initiate slip zones. Quartz tends not to be incorporated into the slip zones (Figure 12d). Slip zones rather anastomoze around larger Qtz survivor grains.

The ratio between Plg and $\mathrm{Kfs}$ as well as Bt and Wm remains approximately constant in both bulk shear zones as well as slip zones $(\sim 1: 1$, Figures $12 \mathrm{c}$ and $12 \mathrm{~d})$, indicating that the slip zones become depleted in quartz. Feldspar-derived PAM often contains $\mathrm{Ca}, \mathrm{Na}$, and $\mathrm{K}$ in proportions not observed in original Plg or Kfs grains (original Plg grains are richer in $\mathrm{Na}$ and $\mathrm{Ca}$ and original $\mathrm{Kfs}$ grains are richer in $\mathrm{K}$ compared to the PAM) indicating a high mobility of alkalis in the PAM [cf. Yund et al., 1990; Pec et al., 2012a, 2012b; Hadizadeh et al., 2015]. The high surface-to-volume ratio, short diffusion distances between grains, and the high defect density in the nanocrystalline partly amorphous material are expected to enhance diffusion [Suryanarayana, 2001] and may explain the observed compositional change of the PAM.

Weakening after peak strength appears to occur once the PAM is sufficiently abundant to form an interconnected, anastomozing network of slip zones ( 7-12 vol \%, Figure 12b), into which the strain partitions. During progressive deformation, a few percent of the PAM transforms even further into amorphous material (AM). In some cases, fragmented mineral grains are offset by a slip zone and can be used to estimate the strain within the slip zone. These offsets reveal that the local shear strain in PAM containing slip zones is always higher than the bulk finite strain by a factor of approximately 2.5 in low strain samples (e.g., $\gamma_{\text {slipzone }}>5$ at $\gamma_{\text {bulk }} \sim 2$ ). In AM-containing slip zones of high strain samples the factor is $>5\left(\gamma_{\text {slipzone }}>20\right.$ at $\left.\gamma_{\text {bulk }} \sim 4\right)$. This strain localization suggests that PAM and AM are weaker and accommodate more strain than the surrounding aggregates. In addition, it points to a strain and strain rate increase within the AM compared to PAM.

It is interesting to note that while the PAM is mostly formed of feldspars, the AM usually has mica as the precursor material. Micas form 8\% of the slip zones (Figure 12d), and the AM layers which consist of more than $99 \%$ of nondiffracting material (Figures $15 \mathrm{e}-15 \mathrm{~g}$ ) with very few crystals of $\sim 5 \mathrm{~nm}$ in size have a similar $z$ contrast as biotite. Euhedral crystals which would indicate growing from a melt were never observed. Lenses of PAM material are often found embedded in $A M$ material (Figure 15c), and AM material is never found in experiments sheared to low finite strains. Furthermore, SADP patterns show a homogenous transition from nanocrystalline to TEM-amorphous material (Figures 13 and 15). These observations indicate that there is a progressive transition from PAM to AM.

The volume fraction of slip zones increases with increasing strain (Figure 12b), which indicates that either the PAM or AM volumes are insufficient to accommodate bulk sample strain, or that they strain harden, or that the slip zones do not operate continuously during the whole experiment and become inactive once their orientation is not favorable for further slip [Holyoke and Tullis, 2006]. In any case, strain accommodation in slip zones is insufficient to keep up with bulk sample deformation rates. We further observe that the amount of slip zones increases as temperature increases (i.e., slip zones cover the largest area fractions at $600^{\circ} \mathrm{C}$ and $10^{-3} \mathrm{~s}^{-1}$ despite deformation at lower stresses compared to lower temperature experiments at the same strain rate; Figures 4 and 12b).

It appears that the PAM and AM in the slip zones behave as viscous, fragment-loaded turbulent fluids and thus are likely candidates to explain the viscous component observed in the mechanical data, i.e., the temperature and strain rate dependence. The exact deformation mechanisms active in the slip zones are not clear yet, but it is likely that the AM deforms by shear transformation zones as commonly inferred for deformation of amorphous materials [e.g., Schuh et al., 2007; Falk and Langer, 2011]. The nonporous, nanocrystalline PAM is thought to deform either by grain boundary sliding [Raj and Ashby, 1971; Hansen et al., 2011] or by a component of shear transformation in their amorphous matrix.

\subsection{Origin of Nanocrystalline, Partly Amorphous, and Fully Amorphous Material}

One peculiar feature of our shearing experiments is the formation of nanocrystalline, partly amorphous (PAM), and fully amorphous material (AM) in zones that accommodate large strains. Observations down to TEM scales confirm that the material is amorphous, but they do not supply direct information about the processes, which caused the crystalline-to-amorphous transition. In principle, there are a number of possible processes: heterogeneous or homogeneous melting and heterogeneous or homogeneous amorphization [Wolf et al., 1990; Fecht, 1992; Yip et al., 2005]; all of which lead to a volume change and thus to a decrease of the shear modulus (Born criterion, as discussed by Wolf et al. [1990] and Yip et al. [2005]; see 
also Machon et al. [2014]). The temperature increase during the formation of the PAM and AM layers is inferred to be negligible (as the slip velocities are slow and heat conduction high) and therefore we favor an amorphization process [Pec et al., 2012b].

Amorphous material during deformation of granitoid fault rocks was also observed by Yund et al. [1990] and Hadizadeh et al. [2015] in a TEM study of high strain $(\gamma » 100)$ rotary friction experiments on granitoid gouges under low normal stresses (25-75 MPa) at room temperature. These studies observed amorphous material with a composition commonly between K-rich and $\mathrm{Na}$-, Ca-rich feldspars as seen in our experiments. Yund et al. [1990] estimated a temperature increase of $\sim 0.02^{\circ} \mathrm{C}$ on the sliding surface and argued that the amorphous material did not form by frictional melting (as the sliding velocities were slow $\sim 10^{-9}-10^{-3} \mathrm{~m} \mathrm{~s}^{-1}$ ) but by comminution of mostly feldspar grains (in agreement with our observations and temperature increase estimates) [Pec et al., 2012a, 2012b].

Amorphization occurs, for example, due to pressure [e.g., Mishima et al., 1984; Kingma et al., 1993] (see Sharma and Sikka [1996], Richet and Gillet [1997], and Machon et al. [2014] for reviews) or during severe deformation (see, e.g., Suryanarayana [2001] for a review, [Lund and Schuh, 2003]). Examples of amorphous materials, which did not form by melting, have been identified in experimentally deformed samples [e.g., Yund et al., 1990; Goldsby and Tullis, 2002; Di Toro et al., 2004; Hayashi and Tsutsumi, 2010; Pec et al., 2012a, 2012b; Nakamura et al., 2012; Amiguet et al., 2014; Hadizadeh et al., 2015; Toy et al., 2015] as well as in natural fault rocks [e.g., Ozawa and Takizawa, 2007; Janssen et al., 2010; Kirkpatrick et al., 2013; see also Faber et al., 2014; Rowe and Griffith, 2015]. Typically, the presence of amorphous material is confined to localized zones, which have accommodated large strains, indicating that amorphous material may have an important influence on the rheological properties of faults.

\subsection{Microstructural Evolution}

The microstructural record shows widespread comminution indicative of cataclastic flow and the development of nonporous, nanocrystalline, partly amorphous to fully amorphous slip zones. The microstructure is primarily controlled by the amount of finite strain accommodated by the samples. Secondary controlling parameters are stress/temperature, confining pressure, and displacement/strain rate. Deformation partitions into slip zones of PAM/AM separating lenses of fragmented material containing survivor grains. Both, the slip zones and the lenses, need to accommodate deformation when the lenses slide past one another. Strain partitions into the slip zones implying that they are weaker than the surrounding lenses. However, as fracturing and strain hardening probably occur on the sample scale, together with preferential appearance of PAM and AM on high stress sites, it appears that high stresses are necessary for the production of PAM and AM (Figures 4 and 6).

Local shear strain rates may vary by 1-2 orders of magnitude within our samples due to strain partitioning and localization. However, this does not imply an increase in slip velocity $(\dot{\gamma}=\dot{d} /$ deforming volume) of the bulk sample, i.e., high strain rates can be achieved at slow displacement rates given that the actively deforming volume is small. The apparent viscosity of the slip zone material can be roughly estimated as $\eta=\tau / \dot{\gamma}_{\text {slip zone }}$ if we assume a constant stress boundary condition. This implies that the PAM and AM have a relatively lower apparent viscosity than the granular aggregates because they deform at faster rates: $\eta_{\text {bulk }} \approx 5 \times 10^{11}-5 \times 10^{13} \mathrm{~Pa} \mathrm{~s}$, while $\eta_{\text {slip zone }} \approx 10^{9}-10^{12} \mathrm{~Pa}$ s. The occurrence of laminar to turbulent flow structures is consistent with a lower viscosity of PAM and AM. In summary, it appears that the semi-brittle behavior in our experiments arises from the combination of viscous flow in the slip zones and brittle/semi-brittle deformation in the bulk phase aggregates.

An exception to the above described microstructural development are experiments deformed at $600^{\circ} \mathrm{C}$ and slow strain rates $\left(10^{-5} \mathrm{~s}^{-1}\right)$ which are substantially weaker than samples deformed at lower temperatures or faster strain rates. In these samples, interconnected grains are observed, typical of healing microstructures occurring during dissolution-precipitation creep [Tenthorey and Cox, 2006; Keulen et al., 2007, 2008; Giger et al., 2008], both in the bulk shear zones as well as in C' oriented slip zones. Furthermore, the weak development of fragmented mantles and of slip zones indicates that the grain size reduction necessary to produce the PAM is counteracted by grain growth and efficient material transport during dissolution-precipitation creep, inhibiting the buildup of high stresses. In other words, by an increased viscous component of deformation. 


\subsection{Bulk Rheological Behavior}

In the mechanical record, a temperature and strain rate dependence of peak and steady state shear stress is observed (Figures 4 and 6). The shape of the stress-strain curves becomes smoother, i.e., the curves have a well-defined steady state flow stress with increasing temperature, increasing confining pressure, and decreasing strain rate, indicating an increasing contribution of viscous deformation to strain accommodation. The volume occupied by slip zones is generally larger at higher temperatures (Figure 12b), suggesting that they are, at least in part, responsible for the observed viscous component of deformation; however, temperature and strain rate dependent behavior was observed already at temperatures $>300-350^{\circ} \mathrm{C}$ in granitoids if small amounts of water were present [Tullis and Yund, 1980; Blanpied et al., 1995, 1998; Keulen et al., 2007, 2008] and is also commonly observed in experimentally deformed fault rock analogues under "hydrothermal" conditions [Bos and Spiers, 2002a, 2002b; Niemeijer and Spiers, 2006, 2007; Niemeijer et al., 2008]. In these experiments, dissolution-precipitation creep was inferred to be active, and no amorphous phases were reported (however, no TEM investigation was performed in these studies). A more recent TEM study on quartz-clay gouges deformed at elevated temperatures identified nanocrystalline material, but no amorphous material was found [Den Hartog et al., 2014]. In our experiments, clear microstructural evidence for dissolution-precipitation creep is lacking except at the highest temperatures and lowest strain rates (Figure 17).

How can the temperature and stress dependence observed in the mechanical record be quantified? The differential stress in all experiments is larger than the confining pressure, i.e., it is above the Goetze criterion [Kohlstedt et al., 1995] and hence classical constitutive equations for exponential (equation (5)) or power law (equation (4)) creep (based on volume-conserving micromechanical models of diffusion, dislocation glide and climb and grain boundary sliding, and a steady state microstructure) [e.g., Koh/stedt and Hansen, 2015] cannot be applied to the bulk samples. Nevertheless, the overall shape of the stress-strain curves resembles stress-strain curves from materials undergoing viscous flow. As briefly mentioned in section 1, to our knowledge, there is no micromechanical model or theory, which satisfactorily describes the semi-brittle flow regime and which could be used for data fitting.

Exponential creep laws (Peierls-type flow laws) are typically used to fit data from low temperature, high confining pressure and high stress deformation experiments where dislocation glide is inferred to be the dominant deformation mechanism. Attempts to find a global fit to our data based on equation (4) lead to poor numerical convergence indicating that an exponential flow law does not describe adequately our data.

In order to quantify the first-order effect of temperature and strain rate, we prefer to fit our mechanical data to a simple power-law flow law as shown in equation (4) that commonly describes viscous deformation in rocks as well as viscous fluids. If the grain size is neglected (because of the very large grain size range in our samples), this fit yields very high stress exponents $(n \approx 10-140)$ and low activation energies $(Q \approx 80$ $180 \mathrm{~kJ} / \mathrm{mol}$ ) (Figure 7). The stress exponent decreases with increasing temperature, and the activation energy increases with decreasing strain rate, in agreement with an increased contribution of viscous processes at higher temperatures and lower strain rates. Note that the overall low stress dependence on strain rate results in a poor resolution of the stress exponent, which also strongly influences the estimation of the activation energy [see Twiss and Moores, 2007, pp. 485-486]. In summary, neither exponential nor power-law flow laws describe our data satisfactorily.

Confining pressure also has a marked effect on the peak and steady state friction coefficients; both of which decrease linearly with increasing $P_{c}$ (Figure 8c), as already observed by Byerlee [1967]. This is in contrast to the shear stress which increases with increasing confining pressure (Figures $8 \mathrm{a}$ and 9). The friction coefficient of many rocks is remarkably constant with $\mu \approx 0.6$ over a broad range of P-T- $\dot{d}$ conditions [Byerlee, 1978]. The value of $\mu$ is connected to the specific mechanism by which asperities fail during sliding, with $\mu=0.6$ being considered a typical value for brittle fracture of asperities and abrasive wear [Byerlee, 1967; Scholz, 2007, pp. 77]. In our experiments, we observe striations which may be formed by sheared off and smeared out asperities (Figure 16a) as well as by linear ploughing of harder quartz grains through the weaker feldspar matrix (Figure 16b).

Brittle sample-scale failure of the samples occurs only at the fastest experimental displacement rates $\left(10^{-6} \mathrm{~m} \mathrm{~s}^{-1}\right)$ at $T=300^{\circ} \mathrm{C}$ and $P_{c} \approx 500 \mathrm{MPa}$. In these samples, the same type of PAM and AM can be detected as in those samples which did not fail abruptly (see Figures 13 and 15), i.e., PAM and AM form both in samples 

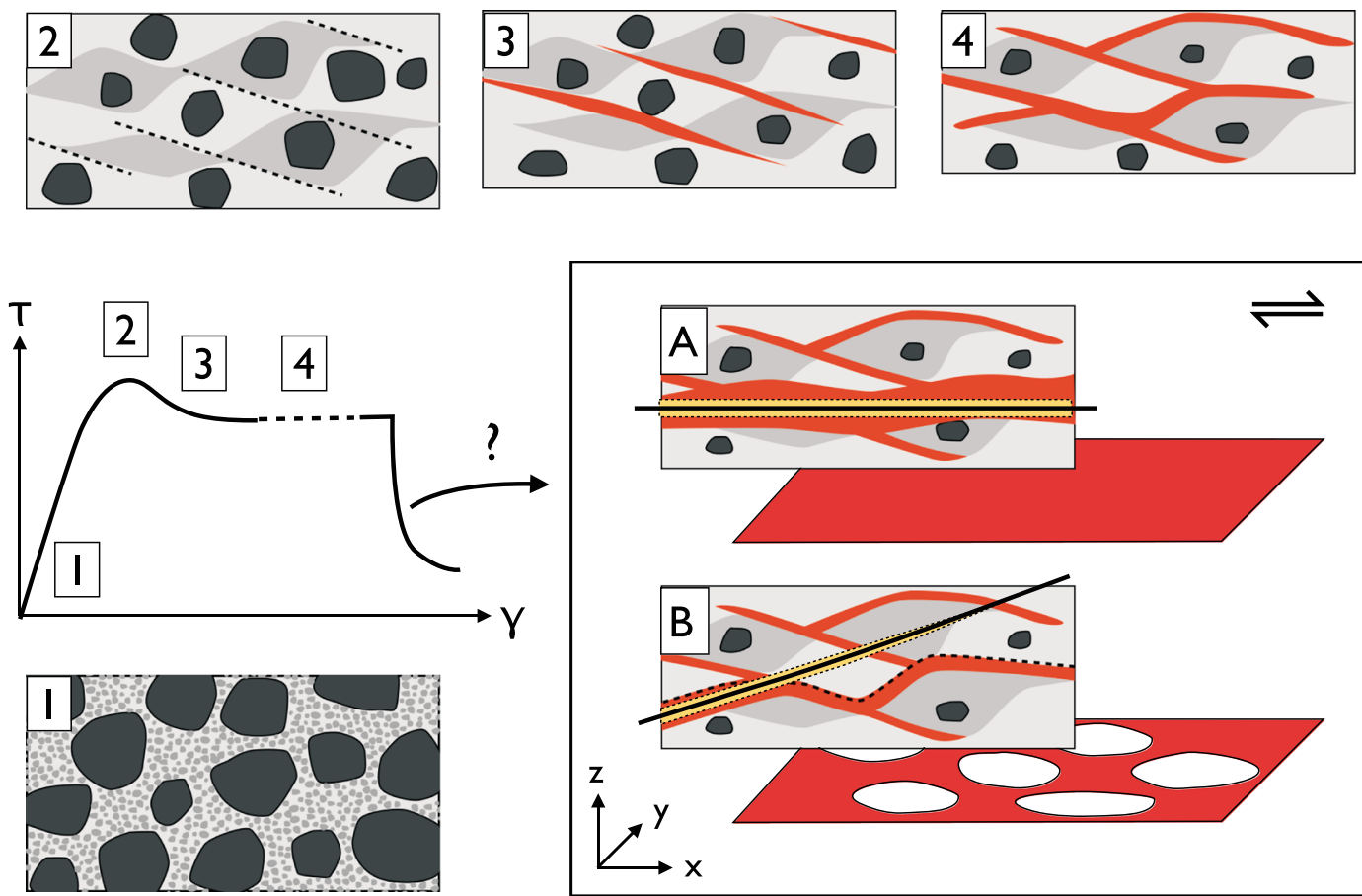

Figure 18. Conceptual model for rheological behavior of faults. Typical stress-strain curve for experimentally sheared fault zones: four stages are highlighted. Clockwise 1-4: Corresponding schematic of microstructure development. (1) $\gamma=0$, $\sigma_{1}=\sigma_{3}=$ confining pressure, start of experiment, compaction leads to grain comminution, $v_{s}: V_{a} \approx 75 \%$, porosity depends on temperature and is on the order of a few percent. (2) $\gamma \approx 1.5$, maximum shear stress, formation of Riedel shears (dashed lines) in $C^{\prime}$ orientation, massive grain comminution, $V_{s}: V_{a} \approx 30 \%$. (3) $\gamma \approx 2$, begin of mechanical steady state after slight weakening, further comminution of survivor grains, $V_{s}: V_{a} \approx 20 \%$, formation of slip zones (red) in C' orientation, $V_{s z} \approx 10 \%$. (4) Sustained mechanical steady state, shear stress remains high, slip zones (red) grow and coalesce in $C^{\prime}$ and $S$ orientation, $V_{s z} \approx 20 \%$, further comminution of survivor grains, $V_{s}: V_{a} \approx 10 \%$. $V_{s}=$ volume of survivor grains, $V_{a}=$ volume of aggregates (survivor grains + fragmented mantle), $V_{s z}=$ volume of slip zone material. Lower right: possible scenarios for abrupt failure. Slip zones consisting of PAM and AM shown in red, $x-y$ view of slip zone topology shown also. (a) Formation of fully connected slip zone through continued growth and coalescence $\rightarrow$ reduction of load bearing bridges of (strong) fragmented fault rock $\rightarrow$ complete mechanical separation of two sides $\rightarrow$ accelerated stain within (weak) PAM and AM of slip zone $\rightarrow$ formation of kinematically viable slip surface (black line). (b) Geometric locking of opposing sides of (strong) fragmented fault rock $\rightarrow$ stress buildup on asperities (outlined with dashed line) $\rightarrow$ brittle failure of fault rock and of multiply connected slip zone network $\rightarrow$ injection of slip zone material (PAM and AM) along fracture. In both cases, shear heating can further weaken PAM and AM, possibly producing frictional melt (orange).

that creep continuously over several days as well as in samples that fail catastrophically. Thus, the formation of PAM and AM in itself cannot be the direct cause for the abrupt failure in our experiments. We therefore infer that it is the microstructural and rheological evolution of the PAM and AM layers that ultimately lead to sample-scale failure, as will be discussed below.

\subsection{Rheological Behavior of Slip Zones}

We propose two basic scenarios for sample-scale failure which may also apply to natural faults (Figure 18): (A) abrupt failure of a fully connected weak layer of slip zone material and (B) brittle failure of the load-bearing fragmented material due to stress concentration.

In case (A) failure may occur if a significant volume fraction of PAM/AM weakens abruptly, either by crossing the glass transition temperature or by reaching the ductile limit (causing delayed brittle fracture). In case (B) stress concentrations may form at the tips of slip zones or at asperities due to slip incompatibility. Once the stresses are high enough, the adjacent crystalline aggregate may fracture leading to sample-scale failure.

\subsubsection{Abrupt Failure of the Slip Zone}

Amorphous materials exhibit a wide range of rheological behavior from solid like to fluid like and hence are described in terms of viscoelastic rheology. Depending on many parameters (presence of second-phase 
particles, chemical composition, bond strength, and temperature difference with respect to the glass transition temperature, $T_{\mathrm{g}}$ ), amorphous materials can be either very "weak" (i.e., accommodate strain at low shear stresses) or very "strong" (i.e., support high shear stresses without straining), [e.g., Falk and Langer, 2011; Suryanarayana, 2001; Schuh et al., 2007].

In as much as the material in the slip zones is amorphous it cannot-by definition-melt (i.e., transform from a crystalline solid into a liquid); however, it could undergo a glass transition where the viscosity of the material is strongly reduced. Such a strong reduction of viscosity could lead to an abrupt failure (=Figure 18, case A). Typical estimates of the glass transition temperature, $T_{g}$, are around two thirds of the melting temperature, $T_{m}$, of the glass-forming material [e.g., Debenedetti and Stillinger, 2001]. The eutectic melting point of wet granite at our experimental condition is $650^{\circ} \mathrm{C}-720^{\circ} \mathrm{C}$, so one could expect an approximate $T_{g}$ of $430-480^{\circ} \mathrm{C}$ for a glass with granitic composition. The amorphous material in our slip zones, however, has a very heterogeneous yet significantly different chemical composition from that of an eutectic granitic melt (it is in general more ferromagnesian and less silica rich, i.e., more mica and feldspar rich) [Pec et al., 2012b] which would imply a higher melting temperature $\left(T_{m}=800^{\circ} \mathrm{C}-850^{\circ} \mathrm{C}\right)$ as well as glass transition temperature $\left(T_{g}=530^{\circ} \mathrm{C}-570^{\circ} \mathrm{C}\right)$. These estimates of $T_{g}$ are in the upper range of our experimental temperatures. Nevertheless, the amorphous material in the slip zones shows similar microstructures in all conducted experiments independent of temperature. Estimates of temperature increase due to frictional heating are on the order of a few degrees Celsius due to the slow deformation velocity and high heat flux in the experimental assembly [Pec et al., 2012b], and hence, frictional heating seems unlikely to significantly increase the temperature above the set experimental temperature $\left(300^{\circ} \mathrm{C}-600^{\circ} \mathrm{C}\right)$. Without an independent estimation of the $T_{g}$ of the amorphous material in the slip zones it is difficult to conclude whether the amorphous material deforms above or below the glass transition temperature.

Another failure possibility is given by the viscoelastic nature of the PAM and AM. The superposition of elastic deformation on irreversible viscous flow causes a complex behavior. Elastic energy is accumulated during deformation due to the distortion of individual atoms in the material by an externally applied force. This buildup of elastic energy is counteracted by material reorganization aided by diffusion, which maintains strain compatibility and allows flow. Therefore, amorphous materials can exhibit a temperature and time (strain rate) dependent rheological behavior, similar to crystalline solids. Depending on the P-T- $\dot{\gamma}$ conditions, the material will either flow or fracture as determined by the dimensionless Deborah number [Reiner, 1964], $D e=t_{c} / t_{p}$ where $t_{c}$ is the stress relaxation time and $t_{p}$ is the observation time or stress buildup time, and $D e=0-\infty$. If the buildup of stress is slow enough that the material can efficiently relax the stress under given P-T conditions, the material will flow, i.e., behave as a fluid (low De). On the other hand, if the buildup of stress is fast, and the relaxation processes cannot keep pace at given P-T conditions with the imposed loading, the material will accumulate elastic energy until it—ultimately—cracks, i.e., behaves as a solid (high De). If —under certain P-T- $\dot{\gamma}$ conditions-the PAM or AM attains a high Deborah number (De $\gg 0)$, the material cannot flow anymore and fails abruptly (Figure 18, case A).

\subsubsection{Failure of the Fragmented Fault Rock}

In another scenario, the PAM and AM within the slip zones efficiently accommodate all the imposed strain. In this case, geometrical incompatibility within the fault rock leads to stress buildup in the crystalline loadbearing material which ultimately can result in the fracture of crystalline aggregates causing a sample-scale failure (Figure 18, case B). The fracture propagates both through the fragmented material and the slip zones; the pressurized PAM and AM material are injected along the propagating fracture.

That the PAM and AM are less viscous than the more coarser grained fragmented material can be observed in natural faults as well. Ultracataclasites form flow structures and inject into opening spaces between rock fragments (Figure 19a). Extremely fine grained ultracataclasites, presumably PAM or even AM, can be observed injecting along perfectly planar fractures that probably formed as described in scenario B (Figure 19b).

\subsection{Implications for Natural Fault Zones}

In section 1, we pointed out difficulties in comparing friction to flow; the seemingly trivial difference in treating faults either as thick surfaces or as thin volumes has important consequences for the design of experiments. Contradictory points also emerge when interpreting natural fault zones. In the frictional field, the existence of a preexisting surface is assumed, and therefore, the less deformed wall rock surrounding a fault 
(a)

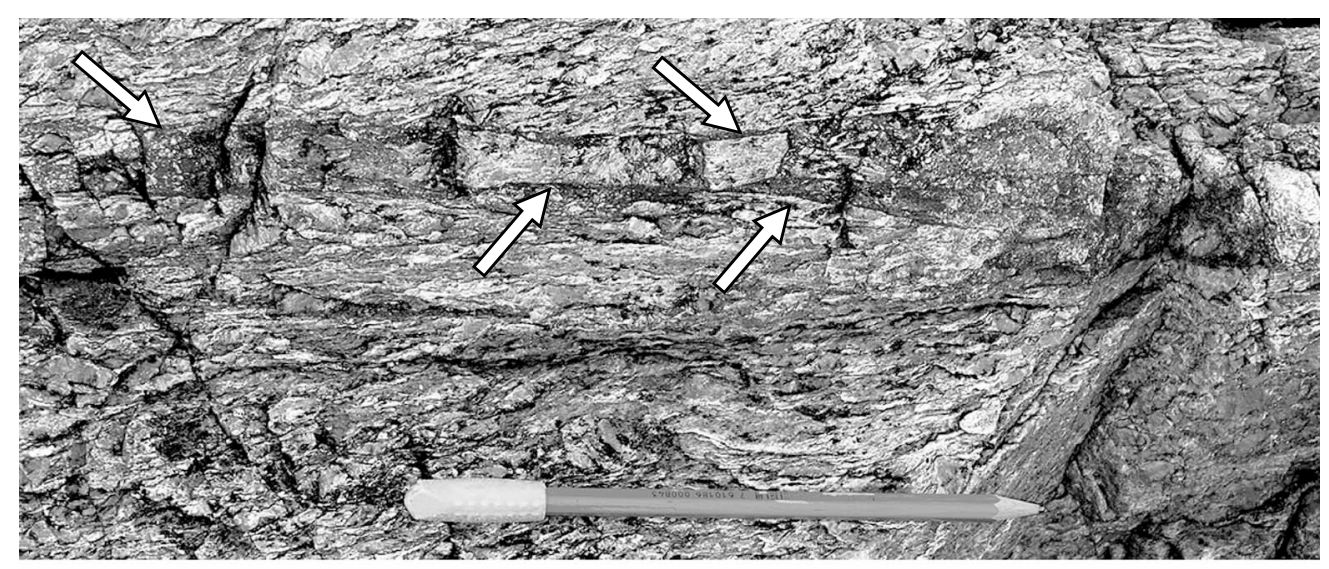

(b)

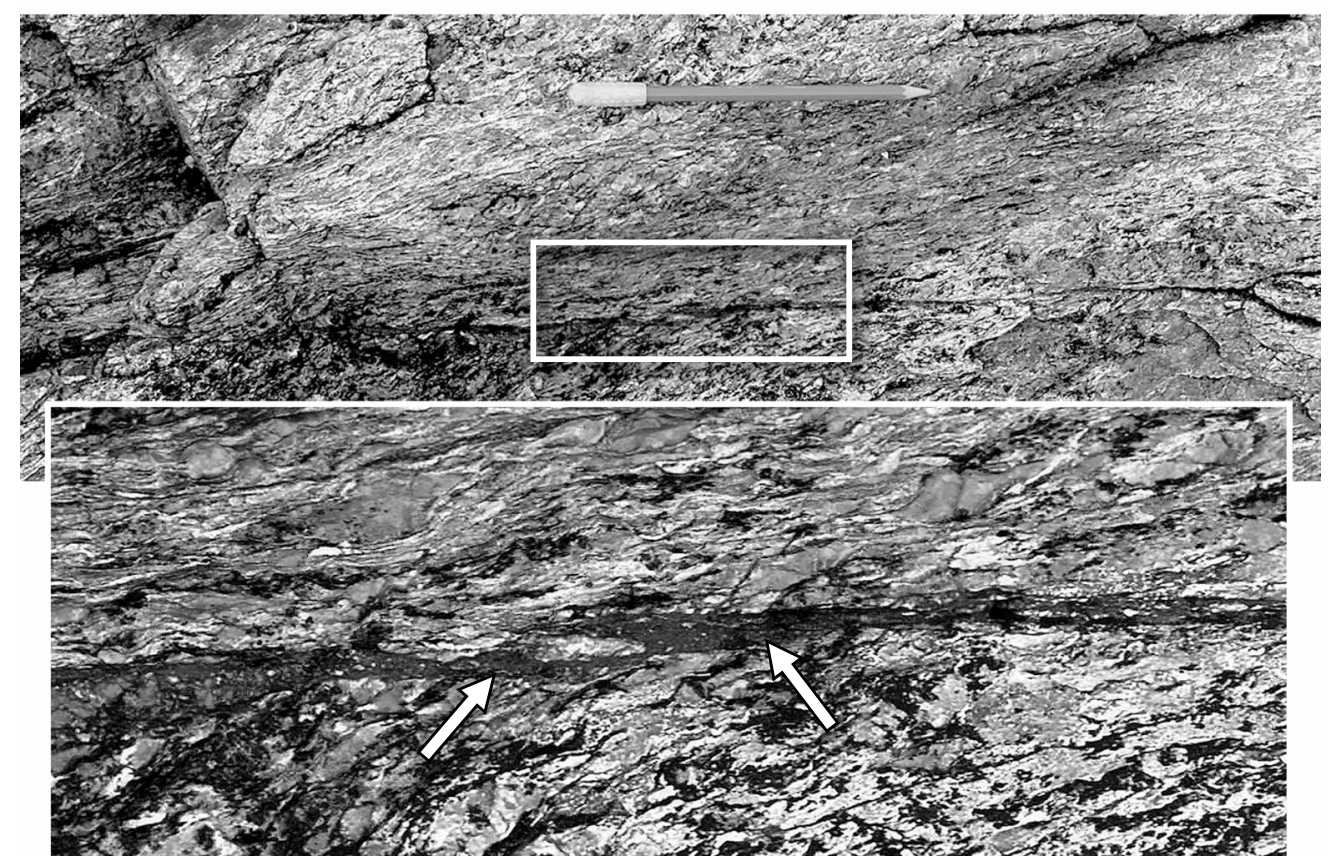

Figure 19. Field examples of fault failure from Grøtfjiord (Norway) (a) Highly mobile PAM/AM (arrow) flowing between disintegrating fragments along fault. (b) Example of failure mode (B) shown in Figure 18: highly mobile PAM/AM injecting into cross-cutting fracture (arrow). Pen is $15 \mathrm{~cm}$ long.

is viewed as a "damage zone," i.e., it forms synchronous with or postdates the fault core. Conversely, in the viscous field the less deformed wall rock surrounding a fault is viewed as a precursor to the development of a high strain shear zone, and therefore, it predates the fault.

Over long timescales, faults accommodate the imposed plate tectonic displacement at a steady state displacement rate. Faults usually branch out and develop a (fractal) anastomosing network with different strands accommodating partial displacements at different rates during the seismic, interseismic, and postseismic deformation periods. A large spread in slip velocities along faults has been identified with displacement rates ranging from $\sim 10^{-12}$ to $\sim 10^{2} \mathrm{~m} \mathrm{~s}^{-1}$ (see Rowe and Griffith [2015] for review). Our experiments cover the lower range of slip velocities approaching plate tectonic displacement rates $\left(\sim 10^{-9}\right.$ to $\left.\sim 10^{-6} \mathrm{~m} \mathrm{~s}^{-1}\right)$. An approximately constant velocity boundary condition seems as the most appropriate for faults, because they have to accommodate rather constant tectonic plate movement. Locally, high stresses may be generated over some periods of time causing semi-brittle flow at the frictional-viscous transition, favoring ultracataclasis, and amorphization of the fault rocks. Amorphous materials could be produced under high-stress, high confining pressure, and low-temperature conditions and might thus trigger earthquakes under a broad range of 
conditions along one of the scenarios described above (Figure 18). Typical conditions where amorphization could occur are on fault asperities, which increase in size in proportion to the applied force so that the material is stressed just to its yield point [e.g., Dieterich and Kilgore, 1994].

\section{Conclusions}

We have conducted an experimental study on granitoid fault rocks under a broad range of temperatures, strain/displacement rates, and confining pressures where the rocks deform by semi-brittle flow, using layers of crushed powder sheared between alumina forcing blocks. Mechanical data show a steady flow stress in all cases except the very fastest and coldest ones which fail abruptly. The strength of the fault rock shows a clear temperature and a weak strain rate dependence. The supported shear stresses increase, and the friction coefficients decrease with increasing confining pressure.

The presence of quartz as the strongest rheological phase facilitates the local buildup of high stresses which then cause comminution and crystal lattice destruction in the minerals with weaker atomic bonds (feldspars and micas) and the formation of a nanocrystalline, partly amorphous material (PAM). An anastomozing network of PAM, i.e., of slip zones develops quickly and when peak strength is reached, it is already interconnected. In some cases, continued strain partitions into the PAM which is progressively transformed into an amorphous material (AM). We infer that the PAM and AM did not form by melting but rather by solid-state amorphization. Slip zones (consisting of PAM and AM) are mechanically weaker than the fault rock as evidenced by flow structure and injection veins.

Obviously, the mechanical behavior of faults in the range of pressure, temperature, and strain rate characteristic of semi-brittle flow is complex. While the layer of fault rock as a whole continues to deform at constant stress levels, the slip zone network continues to develop, percolating through the shear zone, reaching $20 \mathrm{vol} \%$ or more. Two possible modes of bulk failure are envisaged: one where the slip zones form a through-going zone of weakness and one where high stress concentrations at the interface between slip zone and fault rock cause the fault to fail by brittle fracture. In this manner PAM/AM slip zones could trigger earthquakes under a broad range of pressure and temperature conditions where frictional sliding is unlikely and after long periods of slow creep.

\section{Acknowledgments}

All data necessary to evaluate and build upon this work are included in the figures and tables; the data can also be obtained in electronic form by contacting the authors. This paper has benefited from discussion with many friends and colleagues over a very long period of time. Particularly, we wish to thank Rüdiger Kilian, Alejandra QuintanillaTerminel, Ben Holtzman, Michel Bestmann, Brigitte Vogt, Sina Marti, Luca Menegon, Benoit Cordonnier, Gill Pennock, Neil Mancktelow, Marco Herwegh, Christian De Capitani, Alexandre Schubnel, Mark Zimmerman and Jake Tielke for stimulating discussions. Michel Bestmann is also gratefully acknowledged for providing the SEM micrographs shown in Figures $15 \mathrm{c}$ and 15d. Willy Tschudin, Hans-Rudolf Rüegg, Asle Liletum, Silvio Mini, Steinar Ivarsen, the ZMB team, Matthijs de Winter, and Hans Meeldijk are thanked for invaluable technical assistance. Constructive reviews by Elodie Amiguet and an anonymous reviewer have improved the clarity of this paper and are greatly appreciated. Funding by Swiss National Fonds grant 200020-129976 is gratefully acknowledged.

\section{References}

Amiguet, E., B. Van De Moortèle, P. Cordier, N. Hilairet, and B. Reynard (2014), Deformation mechanisms and rheology of serpentines in experiments and in nature, J. Geophys. Res. Solid Earth, 119, 4640-4655, doi:10.1002/2013JB010791.

Beeler, N. M., T. E. Tullis, A. K. Kronenberg, and L. A. Reinen (2007), The instantaneous rate dependence in low temperature laboratory rock friction and rock deformation experiments, J. Geophys. Res., 112, B07310, doi:10.1029/2005JB003772.

Blanpied, M. L., D. A. Lockner, and J. D. Byerlee (1991), Fault stability inferred from granite sliding experiments at hydrothermal conditions, Geophys. Res. Lett., 18(4), 609-612.

Blanpied, M. L., D. A. Lockner, and J. D. Byerlee (1995), Frictional slip of granite at hydrothermal conditions, J. Geophys. Res., 100, 13,045-13,064.

Blanpied, M. L., C. Marone, D. A. Lockner, J. D. Byerlee, and D. P. King (1998), Quantitative measure of the variation in fault rheology due to fluid-rock interactions, J. Geophys. Res., 103, 9691-9712, doi:10.1029/98JB00162.

Bos, B., and C. J. Spiers (2002a), Fluid-assisted healing processes in gouge-bearing faults: Insights from experiments on a rock analogue system, Pure Appl. Geophys., 159(11), 2537-2566.

Bos, B., and C. J. Spiers (2002b), Frictional-viscous flow of phyllosilicate-bearing fault rock: Microphysical model and implications for crustal strength profiles, J. Geophys. Res., 107(B2), 2028, doi:10.1029/2001JB000301.

Bos, B., C. J. Peach, and C. J. Spiers (2000), Frictional-viscous flow of simulated fault gouge caused by the combined effects of phyllosilicates and pressure solution, Tectonophysics, 327(3-4), 173-194.

Boutareaud, S., T. Hirose, M. Andréani, M. Pec, D.-G. Calugaru, A.-M. Boullier, and M.-L. Doan (2012), On the role of phyllosilicates on fault lubrication: Insight from micro- and nanostructural investigations on talc friction experiments, J. Geophys. Res., 117, B08408, doi:10.1029/ 2011 JB009006.

Brace, W. F., and D. L. Kohlstedt (1980), Limits on lithospheric stress imposed by laboratory experiments, J. Geophys. Res., 85, 6248-6252, doi:10.1029/JB085iB11 p06248.

Brace, W. F., E. Silver, K. Hadley, and C. Goetze (1972), Cracks and pores: A closer look, Science, 178(4057), 162-164, doi:10.1126/ science.178.4057.162.

Brantut, N., A. Schubnel, and Y. Guéguen (2011), Damage and rupture dynamics at the brittle-ductile transition: The case of gypsum, J. Geophys. Res., 116, B01404, doi:10.1029/2010JB007675.

Byerlee, J. D. (1967), Frictional characteristics of granite under high confining pressure, J. Geophys. Res., 72, 3639-3648, doi:10.1029/ JZ072i014p03639.

Byerlee, J. D. (1978), Friction of rocks, Pure Appl. Geophys., 116, 615-626.

Carter, N. L., and M. C. Tsenn (1987), Flow properties of continental lithosphere, Tectonophysics, 136(1-2), 27-63, doi:10.1016/0040-1951(87) 90333-7.

Chester, F. M. (1994), Effects of temperature on friction: Constitutive equations and experiments with quartz gouge, J. Geophys. Res., 99, 7247-7261. 
Chester, F. M. (1995), A rheologic model for wet crust applied to strike-slip faults, J. Geophys. Res., 100, 13,033-13,044.

Debenedetti, P. G., and F. H. Stillinger (2001), Supercooled liquids and the glass transition, Nature, 410(6825), 259-267.

Den Hartog, S. A. M., D. M. Saffer, and C. J. Spiers (2014), The roles of quartz and water in controlling unstable slip in phyllosilicate-rich megathrust fault gouges, Earth Planets Space, 66(1), 1-9.

Di Toro, G., D. L. Goldsby, and T. E. Tullis (2004), Friction falls towards zero in quartz rock as slip velocity approaches seismic rates, Nature, 427(6973), 436-439.

Dieterich, J. H. (1978), Time-dependent friction and the mechanics of stick-slip, Pure Appl. Geophys., 116(4), $790-806$.

Dieterich, J. H., and B. D. Kilgore (1994), Direct observation of frictional contacts: New insights for state-dependent properties, Pure Appl. Geophys., 143(1-3), 283-302.

Druiventak, A., C. A. Trepmann, J. Renner, and K. Hanke (2011), Low-temperature plasticity of olivine during high stress deformation of peridotite at lithospheric conditions-An experimental study, Earth Planet. Sci. Lett., 311(3), 199-211.

Evans, B., and C. Goetze (1979), The temperature variation of hardness of olivine and its implication for polycrystalline yield stress, J. Geophys. Res., 84, 5505-5524.

Faber, C., C. D. Rowe, J. A. Miller, Å. Fagereng, and J. H. Neethling (2014), Silica gel in a fault slip surface: Field evidence for palaeo-earthquakes?, J. Struct. Geol., 69, 108-121.

Falk, M. L., and J. S. Langer (2011), Deformation and failure of amorphous, solidlike materials, Annu. Rev. Condens. Matter Phys., 2(1), 353-373, doi:10.1146/annurev-conmatphys-062910-140452.

Fecht, H. J. (1992), Defect-induced melting and solid-state amorphization, Nature, 356(6365), 133-135.

Giger, S. B., S. F. Cox, and E. Tenthorey (2008), Slip localization and fault weakening as a consequence of fault gouge strengthening-Insights from laboratory experiments, Earth Planet. Sci. Lett., 276(1-2), 73-84, doi:10.1016/j.epsl.2008.09.004.

Goetze, C., and B. Evans (1979), Stress and temperature in the bending lithosphere as constrained by experimental rock mechanics, Geophys. J. Int., 59(3), 463-478.

Goldsby, D. L., and T. E. Tullis (2002), Low frictional strength of quartz rocks at subseismic slip rates, Geophys. Res. Lett., 29(17), 1844, doi:10.1029/2002GL015240.

Hadizadeh, J., T. E. Tullis, J. C. White, and A. I. Konkachbaev (2015), Shear localization, velocity weakening behavior, and development of cataclastic foliation in experimental granite gouge, J. Struct. Geol., 71, 86-99.

Hansen, L. N., M. E. Zimmerman, and D. L. Kohlstedt (2011), Grain boundary sliding in San Carlos olivine: Flow law parameters and crystallographic-preferred orientation, J. Geophys. Res., 116, B08201, doi:10.1029/2011JB008220.

Hayashi, N., and A. Tsutsumi (2010), Deformation textures and mechanical behavior of a hydrated amorphous silica formed along an experimentally produced fault in chert, Geophys. Res. Lett., 37, L12305, doi:10.1029/2010GL042943.

Heilbronner, R., and S. Barrett (2014), Image Analysis in Earth Sciences: Microstructures and Textures of Earth Materials, Springer, Berlin.

Hirth, G., and J. Tullis (1994), The brittle-plastic transition in experimentally deformed quartz aggregates, J. Geophys. Res., 99, 11,731-11,747, doi:10.1029/93JB02873

Holyoke, C. W., and J. Tullis (2006), The interaction between reaction and deformation: An experimental study using a biotite + plagioclase + quartz gneiss, J. Metamorph. Geol., 24(8), 743-762, doi:10.1111/j.1525-1314.2006.00666.x.

Inoue, K. (1957), The strength of single crystals of inorganic salts under high pressure, Il, Rev. Phys. Chem. Jpn., 27(2), 54-58.

Janssen, C., R. Wirth, E. Rybacki, R. Naumann, H. Kemnitz, H.-R. Wenk, and G. Dresen (2010), Amorphous material in SAFOD core samples (San Andreas Fault): Evidence for crush-origin pseudotachylytes? Geophys. Res. Lett., 37, L01303, doi:10.1029/2009GL040993.

Keulen, N., R. Heilbronner, H. Stünitz, A.-M. Boullier, and H. Ito (2007), Grain size distributions of fault rocks: A comparison between experimentally and naturally deformed granitoids, J. Struct. Geol., 29(8), 1282-1300.

Keulen, N., H. Stünitz, and R. Heilbronner (2008), Healing microstructures of experimental and natural fault gouge, J. Geophys. Res., 113, B06205, doi:10.1029/2007JB005039.

Kingma, K. J., C. Meade, R. J. Hemley, H. K. Mao, and D. R. Veblen (1993), Microstructural observations of $\alpha$-quartz amorphization, Science, $259,666$.

Kirby, S. H., and A. K. Kronenberg (1984), Deformation of clinopyroxenite: Evidence for a transition in flow mechanisms and semibrittle behavior, J. Geophys. Res., 89, 3177-3192.

Kirkpatrick, J. D., C. D. Rowe, J. C. White, and E. E. Brodsky (2013), Silica gel formation during fault slip: Evidence from the rock record, Geology, 41(9), 1015-1018

Kohlstedt, D. L., and L. N. Hansen (2015), Constitutive equations, rheological behavior, and viscosity of rocks, in Treatise on Geophysics, 2nd ed., edited by G. E. Schubert, chap. 2.18, pp. 441-472, Elsevier, Oxford, U. K

Kohlstedt, D. L., B. Evans, and S. J. Mackwell (1995), Strength of the lithosphere: Constraints imposed by laboratory experiments, J. Geophys. Res., 100, 517-587.

Kronenberg, A. K., S. H. Kirby, and J. Pinkston (1990), Basal slip and mechanical anisotropy of biotite, J. Geophys. Res., 95, 19,257-19,278.

Lund, A. C., and C. A. Schuh (2003), Atomistic simulation of strain-induced amorphization, Appl. Phys. Lett., 82(13), 2017-2019, doi:10.1063/1.1563831.

Machon, D., F. Meersman, M. C. Wilding, M. Wilson, and P. F. McMillan (2014), Pressure-induced amorphization and polyamorphism: Inorganic and biochemical systems, Prog. Mater. Sci., 61, 216-282.

Mares, V. M., and A. K. Kronenberg (1993), Experimental deformation of muscovite, J. Struct. Geol., 15(9), 1061-1075.

Marone, C. (1998), Laboratory-derived friction laws and their application to seismic faulting, Annu. Rev. Earth Planet. Sci., 26(1), 643-696.

Mei, S., A. M. Suzuki, D. L. Kohlstedt, N. A. Dixon, and W. B. Durham (2010), Experimental constraints on the strength of the lithospheric mantle, J. Geophys. Res., 115, B08204, doi:10.1029/2009JB006873.

Mishima, O., L. D. Calvert, and E. Whalley (1984), "Melting ice" I at $77 \mathrm{~K}$ and 10 kbar: A new method of making amorphous solids, Nature, 310(5976), 393-395.

Nakamura, Y., J. Muto, H. Nagahama, I. Shimizu, T. Miura, and I. Arakawa (2012), Amorphization of quartz by friction: Implication to silica-gel lubrication of fault surfaces, Geophys. Res. Lett., 39, L21303, doi:10.1029/2012GL053228.

Niemeijer, A. R., and C. J. Spiers (2005), Influence of phyllosilicates on fault strength in the brittle-ductile transition: Insights from rock analogue experiments, Geol. Soc. London, Spec. Publ., 245, 303.

Niemeijer, A. R., and C. J. Spiers (2006), Velocity dependence of strength and healing behaviour in simulated phyllosilicate-bearing fault gouge, Tectonophysics, 427(1-4), 231-253.

Niemeijer, A. R., and C. J. Spiers (2007), A microphysical model for strong velocity weakening in phyllosilicate-bearing fault gouges, J. Geophys. Res., 112, B10405, doi:10.1029/2007JB005008. 
Niemeijer, A. R., C. J. Spiers, and C. J. Peach (2008), Frictional behaviour of simulated quartz fault gouges under hydrothermal conditions: Results from ultra-high strain rotary shear experiments, Tectonophysics, 460(1-4), 288-303, doi:10.1016/j.tecto.2008.09.003.

Noda, $\mathrm{H}_{\text {., }}$ and T. Shimamoto (2010), A rate- and state-dependent ductile flow law of polycrystalline halite under large shear strain and implications for transition to brittle deformation, Geophys. Res. Lett., 37, L09310, doi:10.1029/2010GL042512.

Noda, H., and T. Shimamoto (2012), Transient behavior and stability analyses of halite shear zones with an empirical rate-and-state friction to flow law, J. Struct. Geol., 38, 234-242, doi:10.1016/j.jsg.2011.08.012.

Ohnaka, M. (1995), A shear failure strength law of rock in the brittle-plastic transition regime, Geophys. Res. Lett., 22, 25-28.

Ozawa, K., and S. Takizawa (2007), Amorphous material formed by the mechanochemical effect in natural pseudotachylyte of crushing origin: A case study of the lida-Matsukawa Fault, Nagano Prefecture, Central Japan, J. Struct. Geol., 29(11), 1855-1869, doi:10.1016/j.jsg.2007.08.008.

Paterson, M. S., and T. Wong (2005), Experimental Rock Deformation-The Brittle Field, 2nd ed., Springer, Berlin.

Peč, M. (2014), Experimental investigation on the rheology of fault rocks, PhD thesis, Universität Basel, doi:10.5451/unibas-006285679.

Pec, M., H. Stünitz, R. Heilbronner, M. Drury, and C. de Capitani (2012a), Origin of pseudotachylites in slow creep experiments, Earth Planet. Sci. Lett., 355-356, 299-310, doi:10.1016/j.epsl.2012.09.004.

Pec, M., H. Stünitz, and R. Heilbronner (2012b), Semi-brittle deformation of granitoid gouges in shear experiments at elevated pressures and temperatures, J. Struct. Geol., 38, 200-221, doi:10.1016/j.jsg.2011.09.001.

Raj, R., and M. F. Ashby (1971), On grain boundary sliding and diffusional creep, Metall. Trans., 2(4), 1113-1127.

Reber, J. E., N. W. Hayman, and L. L. Lavier (2014), Stick-slip and creep behavior in lubricated granular material: Insights into the brittle-ductile transition, Geophys. Res. Lett., 41, 3471-3477, doi:10.1002/2014GL059832.

Reber, J. E., L. L. Lavier, and N. W. Hayman (2015), Experimental demonstration of a semi-brittle origin for crustal strain transients, Nat. Geosci., $8,712-715$.

Reiner, M. (1964), The Deborah number, Phys. Today, 17(1), 62, doi:10.1063/1.3051374.

Renner, J., G. Siddiqi, and B. Evans (2007), Plastic flow of two-phase marbles, J. Geophys. Res., 112, B07203, doi:10.1029/2005JB004134.

Renshaw, C. E., and E. M. Schulson (2007), Limits on rock strength under high confinement, Earth Planet. Sci. Lett., 258(1-2), 307-314, doi:10.1016/j.epsl.2007.03.043.

Richet, P., and P. Gillet (1997), Pressure-induced amorphization of minerals: A review, Eur. J. Mineral., 9, 907-934.

Rowe, C. D., and W. A. Griffith (2015), Do faults preserve a record of seismic slip: A second opinion, J. Struct. Geol., 78, 1-26.

Ruina, A. (1983), Slip instability and state variable friction laws, J. Geophys. Res., 88, 10,359-10,370.

Rybacki, E., M. S. Paterson, R. Wirth, and G. Dresen (2003), Rheology of calcite-quartz aggregates deformed to large strain in torsion, J. Geophys. Res., 108(B2), 2089, doi:10.1029/2002JB001833.

Scholz, C. H. (1988), The brittle-plastic transition and the depth of seismic faulting, Geol. Rundschau, 77(1), 319-328.

Scholz, C. H. (1998), Earthquakes and friction laws, Nature, 391(6662), 37-42.

Scholz, C. H. (2007), The Mechanics of Earthquakes and Faulting, Cambridge Univ. Press, Cambridge, U. K.

Schubnel, A., E. Walker, B. D. Thompson, J. Fortin, Y. Guéguen, and R. P. Young (2006), Transient creep, aseismic damage and slow failure in Carrara marble deformed across the brittle-ductile transition, Geophys. Res. Lett., 33, L17301, doi:10.1029/2006GL026619.

Schuh, C. A., T. C. Hufnagel, and U. Ramamurty (2007), Mechanical behavior of amorphous alloys, Acta Mater., 55(12), 4067-4109.

Sharma, S. M., and S. K. Sikka (1996), Pressure induced amorphization of materials, Prog. Mater. Sci., 40(1), 1-77.

Shimada, M. (1993), Lithosphere strength inferred from fracture strength of rocks at high confining pressures and temperatures, Tectonophysics, 217(1-2), 55-64.

Stöckhert, B., M. R. Brix, R. Kleinschrodt, A. J. Hurford, and R. Wirth (1999), Thermochronometry and microstructures of quartz-a comparison with experimental flow laws and predictions on the temperature of the brittle-plastic transition, J. Struct. Geol., 21(3), 351-369.

Suryanarayana, C. (2001), Mechanical alloying and milling, Prog. Mater. Sci,, 46(1-2), 1-184, doi:10.1016/S0079-6425(99)00010-9.

Tajčmanová, L., R. Abart, R. Wirth, G. Habler, and D. Rhede (2012), Intracrystalline microstructures in alkali feldspars from fluid-deficient felsic granulites: A mineral chemical and TEM study, Contrib. Mineral. Petrol., 164(4), 715-729.

Tarantola, A., L. Diamond, H. Stünitz, A. Thust, and M. Pec (2012), Modification of fluid inclusions in quartz by deviatoric stress. III: Influence of principal stresses on inclusion density and orientation, Contrib. Mineral. Petrol., 164(3), 537-550.

Tenthorey, E., and S. F. Cox (2006), Cohesive strengthening of fault zones during the interseismic period: An experimental study, J. Geophys. Res., 111, B09202, doi:10.1029/2005JB004122.

Toy, V. G., T. M. Mitchell, A. Druiventak, and R. Wirth (2015), Crystallographic preferred orientations may develop in nanocrystalline materials on fault planes due to surface energy interactions, Geochem. Geophys. Geosyst., 16, 2549-2563, doi:10.1002/2015GC005857.

Tullis, J., and R. A. Yund (1980), Hydrolytic weakening of experimentally deformed Westerly granite and Hale albite rock, J. Struct. Geol., 2(4), 439-451.

Tullis, J., and R. A. Yund (1987), Transition from cataclastic flow to dislocation creep of feldspar: Mechanisms and microstructures, Geology, 15(7), 606-609.

Twiss, R. J., and E. M. Moores (2007), Structural Geology, 736 pp., W. H. Freeman, New York.

Underwood, E. E. (1970), Quantitative Stereology, Addison-Wesley Ser. in Metall. and Mater., Addison-Wesley, Reading, Mass.

Verberne, B. A., O. Plümper, D. A. M. de Winter, and C. J. Spiers (2014), Superplastic nanofibrous slip zones control seismogenic fault friction, Science, 346(6215), 1342-1344.

Violay, M., B. Gibert, D. Mainprice, B. Evans, J.-M. Dautria, P. Azais, and P. Pezard (2012), An experimental study of the brittle-ductile transition of basalt at oceanic crust pressure and temperature conditions, J. Geophys. Res., 117, B03213, doi:10.1029/2011JB008884.

Viti, C. (2011), Exploring fault rocks at the nanoscale, J. Struct. Geol., 33(12), 1715-1727, doi:10.1016/j.jsg.2011.10.005.

White, S. (2001), Textural and microstructural evidence for semi-brittle flow in natural fault rocks with varied mica contents, Int. J. Earth Sci., 90(1), 14-27.

Wolf, D., P. R. Okamoto, S. Yip, J. F. Lutsko, and M. Kluge (1990), Thermodynamic parallels between solid-state amorphization and melting, J. Mater. Res., 5(2), 286-301, doi:10.1557/JMR.1990.0286.

Yip, S., S. R. Phillpot, and D. Wolf (2005), Crystal disordering in melting and amorphization, in Handbook of Materials Modeling, edited by S. Yip, pp. 2009-2023, Springer, Dordrecht, Netherlands.

Yund, R. A., M. L. Blanpied, T. E. Tullis, and J. D. Weeks (1990), Amorphous material in high strain experimental fault gouges, J. Geophys. Res., $95,15,589-15,602$. 